Identification of a novel class of potent and selective small molecule FXR agonists based on the benzimidazolyl-acetamide scaffold

G. M. Benson, ${ }^{\mathrm{a}}$ K. H. Bleicher, ${ }^{\mathrm{a}}$ D. Blum, ${ }^{\mathrm{a}}$ E. Chaput, ${ }^{\mathrm{a}}$ N. Clemann, ${ }^{\mathrm{a}} \mathrm{S}$. Feng, ${ }^{\mathrm{b}}$ C. Gardes, ${ }^{\mathrm{a}}$ U. Grether, ${ }^{\mathrm{a}}$ P. Hartman, ${ }^{\mathrm{a}}$ B. Kuhn, ${ }^{\mathrm{a}}$ R. E. Martin, ${ }^{\text {a }}$ J.-M. Plancher, ${ }^{\mathrm{a}}$ H. G. F. Richter, ${ }^{\mathrm{a}}$ M. G. Rudolph, ${ }^{\mathrm{a}}$ F. Schuler, ${ }^{\mathrm{a}}$ S. Taylor ${ }^{\mathrm{a}}$

${ }^{a}$ F. Hoffmann-La Roche Ltd, Pharmaceutical Research, Grenzacherstrasse, CH-4070 Basel, Switzerland

${ }^{\mathrm{b}}$ Roche R\&D Center (China) Ltd, 720 Cai Lun Road, Building 5, Pudong, Shanghai 201203, China

The Farnesoid $\mathrm{X}$ receptor (FXR) is a ligand-activated transcription factor and a member of the nuclear hormone receptor family. ${ }^{[1]}$ FXR is a key sensor for bile acids and is mainly expressed in liver, intestine, kidney and adrenal glands where it acts as an important regulator of genes involved in diverse metabolic pathways including bile acid, cholesterol, lipid, lipoprotein and glucose homeostasis. Therefore, FXR modulators could have a great therapeutic potential in the treatment of dyslipidemia, atherosclerosis, cholestasis, diabetes, NASH and diabetic kidney disease. ${ }^{[2]}$

A high-throughput screen of the Roche compound collection led to the discovery of benzimidazolyl-acetamides as a novel class of potent FXR agonists. Optimization of the original lead structures ${ }^{[3]}$ to improve bioavailability and reduce hERG affinity by applying structure-based design, yielded compounds endowed with excellent physicochemical and ADME properties displaying potent plasma lipid lowering effects in $\mathrm{LDLR}^{-/-}$mice after oral administration. ${ }^{[4]}$ In the presentation the synthesis, structure-activity- and structure-property relationships of this novel class of non-steroidal FXR agonists will be described.

[1] B. Staels et al., Physiol. Rev. 2009, 89, 147.

[2] Y. Zhang, P. A. Edwards, FEBS Lett. 2008, 582, 10.

[3] K. H. Bleicher et al., Bioorg. Med. Chem. Lett. 2011, 21, 191.

[4] H. G. F. Richter et al., Bioorg. Med. Chem. Lett. 2011, 21, 1134.

\section{Medicinal Chemistry}

MC 3

A potent Jak3 inhibitor with high selectivity within the Janus kinase family - On the roles of Jak1 and Jak3 in signal transduction

\section{Gebhard Thoma}

Novartis Institutes for BioMedical Research, Forum 1, Novartis Campus, CH-4002 Basel, Switzerland

We describe the discovery of potent Jak3 inhibitor 1 with high selectivity within the Jak kinase family. We provide a rationale for this unprecedented selectivity based on the X-ray crystal structure of an analogue of 1 bound to Jak3. Compound 1 exhibited surprisingly poor potency in cellular assays depending on both Jak1 and Jak3. As Jak3 always cooperates with Jak1 for signaling, we speculated that specific inhibition of Jak3 is not sufficient to efficiently block signal transduction. We will present data supporting this hypothesis.

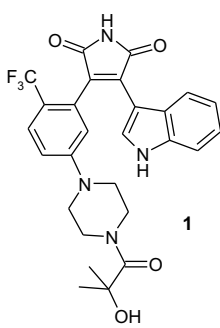

[1] Thoma, Gebhard; Nuninger, Francois; Falchetto, Rocco; Hermes, Erwin; Tavares, Gisele A.; Vangrevelinghe, Eric; Zerwes, Hans-Günter; $J$. Med. Chem. 2011, 54, 284.

[2] Haan, Claude; Rolvering, Catherine; Raulf, Friedrich; Kapp, Manuela; Drückes, Peter; Thoma, Gebhard; Behrmann, Iris; Zerwes, HansGünter; Chem. Biol. 2011, 18, 2 .

\section{A New Synthetic Approach to Side Chain-Modified Analogs of Cyclopropyl-Epothilone B}

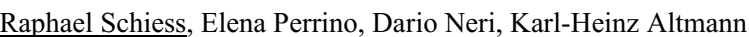 \\ ETH Zürich, Institute of Pharmaceutical Sciences, \\ Wolfgang-Pauli-Strasse 10, HCI, CH-8093 Zürich, Switzerland
}

Epothilones (Epo's; Scheme 1) are microtubule-stabilizing agents with potent antitumor activity. ${ }^{[1]}$ Initially isolated from the myxobacterium Sorangium cellulosum with Epo A and B as the major variants, epothilones have served as important lead structures for anticancer drug discovery. ${ }^{[1]}$ Among numerous other modifications, ${ }^{[1]}$ the replacement of the epoxide ring by a metabolically more stable cyclopropane moiety has been shown to be well tolerated and the same is true for a variety of side chain modifications. In a project that aims at the construction of antibody-drug conjugates we have now prepared a series of side chain-modified analogs of cyclopropyl-Epo B $\mathbf{1}$ and we have evaluated their antiproliferative activity.

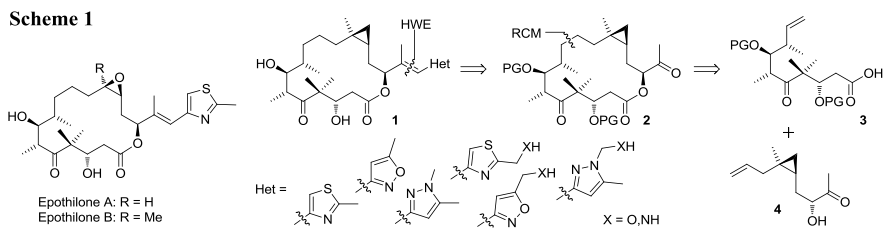

The synthesis of analogs of $\mathbf{1}$ is based on a novel, flexible approach towards the cyclopropyl-Epo B scaffold that relies on late stage introduction of the side chain through HWE chemistry and ring closure by RCM (Scheme 1). This contribution will discuss the synthesis of macrolactone $\mathbf{2}$ from building blocks 3 and $\mathbf{4}$ and its elaboration into the desired target structures. Preliminary results for a first antibody-drug conjugate will be presented.

[1] K.-H. Altmann et al. ChemMedChem 2007, 2, 396.

Medicinal Chemistry

MC 4

Adenosine kinase overexpression leads to a trypanostatic effect in Trypanosoma brucei

$\underline{\text { Patricia Graven }}{ }^{1}$, Margherita Tambalo ${ }^{1}$, Elena Facini ${ }^{1}$, Marc Mosimann $^{2}$, Pascal Mäser ${ }^{2}$, Leonardo Scapozza ${ }^{1}$, Remo Perozzo $^{1}$

${ }^{1}$ Pharmaceutical Biochemistry Group, University of Geneva \& Lausanne, Quai Ernest-Ansermet 30, 1211 Geneva, Switzerland

${ }^{2}$ Institute of Cell Biology, University of Bern, CH-3012 Bern, Switzerland

Few drugs exist for the treatment of Human African Trypanosomiasis (HAT; sleeping sickness), and severe toxic side effects are a common problem. The purine metabolism of Trypanosoma brucei, the causative agent of HAT, provides a valuable target for the development of new drugs as in contrast to mammals, the parasites have no de novo purine biosynthesis and thus depend upon salvage from its hosts to obtain nucleic acids.

Our previous research activities found that 4-[5-(4-phenoxyphenyl)- $2 \mathrm{H}$ pyrazol-3-yl]-morpholine exhibits antitrypanosomal activity with an $\mathrm{IC}_{50}$ of $1 \mu \mathrm{M}$, and chemical proteomics identified Trypanosoma brucei adenosine kinase (TbAK) as the intracellular target. TbAK is involved in the purine salvage pathway. Subsequent biochemical analyses found this compound to be a strong activator of TbAK. The aim of the present project is the genetic validation of TbAK as the intracellular target and the applicability of TbAK hyperactivation as novel strategy to develop trypanocides. To this end we developed a tetracycline inducible $a k$ overexpression strain of $T$. brucei. We hypothesized that overexpression of TbAK compares to hyperactivation in presence of the activator. We constructed a second tetracycline inducible overexpression strain harboring an inactive TbAK (D299V) in order to exclude a possible toxic effect due to the presence of non-physiological high levels of TbAK. The results of wild type and overexpression strains in respect of the parasites viability and the sensitivity towards the activator will be presented. In addition, we complete the study with the analysis of the intracellular purine levels measured by HPLC in order to show TbAK activity in wild type and overexpression strains. 
Medicinal Chemistry

Structure-Based Design and Synthesis of Non-peptidic Novel Inhibitors for the Malarial Target Plasmepsins

Valentina Aureggi ${ }^{1}$, Jörg Wieland ${ }^{2}$, Solange Meyer ${ }^{3}$, Daniel Bur ${ }^{3}$, Bernhard Breit $^{2}$, François Diederich ${ }^{1}$ *

${ }^{1}$ ETH Zurich, Wolfgang-Pauli-Str. 10, CH-8093 Zurich, Switzerland

${ }^{2}$ University of Freiburg, Albertstr. 21, 79104 Freiburg, Germany

${ }^{3}$ Actelion Ltd, Hegenheimermattweg 91, 4123, Allschwil, Switzerland

The increasing number of multi-drug-resistant strains of Plasmodium falciparum which causes the deadliest form of malaria requires the urgent development of new therapeutic agents with novel modes of action. ${ }^{[1]}$

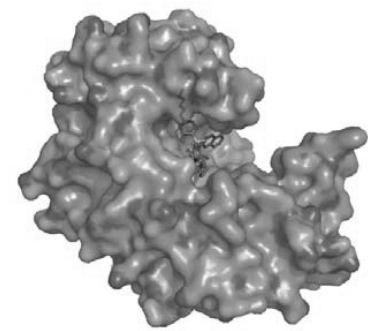

In the presence of a ligand addressing the catalytic dyad with a cyclic amine, a conformational change occurs, and a new characteristic flap-pocket is observed. ${ }^{[2]}$ New inhibitors have been designed to enhance potency, selectivity, and to overcome the resistance against existing antimalarials.

[1] World Health Organization. World Malaria Report 2008 (Geneva). [2] M. Zücher, F. Hof, L. Barandun, A. Schütz, W. B. Schweizer, W. Bernd; S. Meyer, D. Bur, F. Diederich, Eur. J. Org. Chem. 2009, 11, 1707.

Medicinal Chemistry

MC 7

Trypsin inhibitors for the treatment of pancreatitis: A long way from the prime site into the $S 3 / 4$ pocket

\section{Trixi Brandl}

Novartis Institutes for BioMedical Research, CH-4002 Basel, Switzerland

Pancreatitis is a common disease which results from inflammatory processes in the pancreas, characterized by infiltration of inflammatory cells, edema formation, vacuolization of acinar cells and necrosis. It is believed that the premature activation of trypsinogen to trypsin in the pancreas is one of the leading causes for the development of pancreatitis.

In order to identify chemical starting points for the development of trypsin inhibitors, a high throughput screen of the Novartis compound collection was performed, resulting in the discovery of the benzylamine proline hit compound $\mathbf{1}$. The X-ray structure of compound $\mathbf{1}$ bound to trypsin revealed that the inhibitor binds to the S1, S2 and S1 ' pockets of the enzyme, whereas the $S 3 / 4$ pocket - in contrast to most of the literature known inhibitors of other classical S1 serine proteases - remains unoccupied.

In an effort to reduce molecular weight, lipophilicity and hence, to improve the overall profile of the original hit, an integrated approach using X-ray information and modeling was used to develop novel benzylamine proline inhibitors binding in the trypsin $\mathrm{S} 3 / 4$ pocket instead of the prime site.

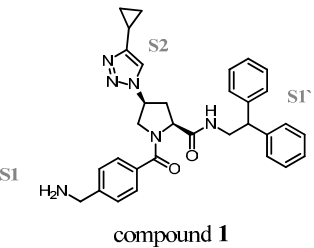

trypsin $\mathrm{IC}_{50}=90 \mathrm{nM}$

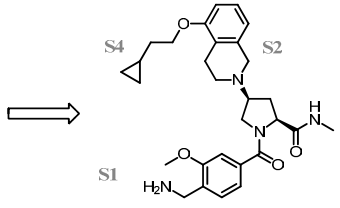

compound 2 trypsin $\mathrm{IC}_{50}=3 \mathrm{nM}$
Medicinal Chemistry

MC 6

\section{Design of Small Molecule Protein-Protein Inhibitors}

\author{
Harald Mauser
}

F Hoffmann-La Roche Ltd., Discovery Chemistry, 4070 Basel, Switzerland

The recent success in efficiently inhibiting protein-protein interaction (PPI) targets has increased confidence in rational design of PPI ligands. To date, several X-Ray and NMR structures of ligand protein complexes for various PPI targets could be solved and laid the foundation for understanding the molecular mechanism and key interaction pattern of PPIs. This positive development stands in strong contrast to the low hit rates generally observed when running high-throughput screening assays against PPI targets. As a consequence, we set out to specifically design libraries targeting proteinprotein interactions. This presentation describes the concept of designing small molecule PPI ligands together with the first results from profiling against an in house panel of PPI targets. Several confirmed actives with molecular weight less or equal to 500 Da clearly demonstrate that rational design of small molecule inhibitors of protein-protein interactions (smPPIs) is indeed feasible.

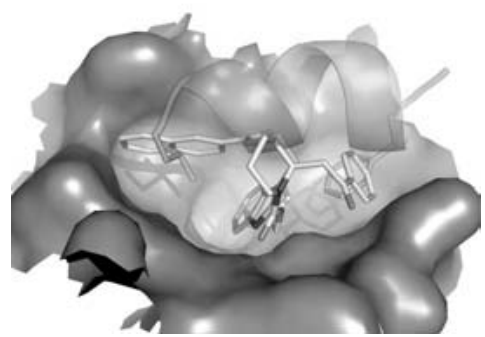

Figure 1: Design template (yellow) docked into the MDM2 binding epitope (grey; pdb code: 1T4F). The key residues of the natural interaction partner p53 are shown in cyan.

Medicinal Chemistry

MC 8

Discovering Protein Targets of Drugs Using Yeast-Based Screen

Cindy Fellay, Christopher Chidley, Kai Johnsson

EPFL, SB-ISIC-LIP, CH-1015 Lausanne, Switzerland

The whole process for new drugs to be approved still takes 10 to 15 years. Therefore, one recent strategy called drug repurposing consists in identifying and developing new uses for already existing drugs [1]. In the last few years a SNAP-based yeast three-hybrid $(\mathrm{Y} 3 \mathrm{H})$ platform has been developed in our group and was shown to be an efficient and easy-to-use tool for target deconvolution [2].

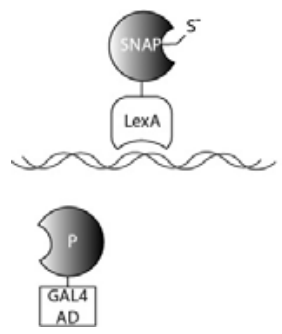

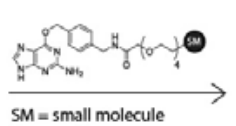

$\mathrm{SM}=$ small molec

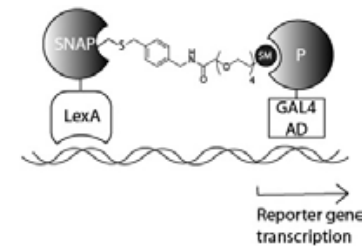

transcription
With this robust $\mathrm{Y} 3 \mathrm{H}$ platform, human protein libraries can be screened for new protein targets of drugs or small molecules in general. The interaction between one protein from a library and a drug covalently attached to SNAPtag leads to transcription of a reporter gene in the nucleus of yeast cells. Several drugs are currently involved in this yeast-based screen in order to identify new drug / protein binding partners.

[1] M. S. Boguski, K. D. Mandl, V. P. Sukhatme, Science 2009, 324, 1394.

[2] C. Chidley, H. Haruki, M. G. Pedersen, E. Muller, K. Johnsson, Nat. Chem. Biol. 2011, in press. 
Design, Synthesis and Biological Evaluation of Mannosyl Triazoles as FimH Antagonists

Oliver Schwardt, Said Rabbani, Matthias Wittwer, Adam Zalewski, Brian Cutting, and Beat Ernst*

Institute of Molecular Pharmacy, University of Basel

Klingelbergstrasse 50, CH-4056 Basel, Switzerland

Urinary tract infection (UTI) caused by uropathogenic E. coli (UPEC) is one of the most prevalent infectious diseases [1]. In the initial step of the infection, the lectin FimH, located at the tip of bacterial pili, interacts with the high-mannosylated uroplakin Ia glycoprotein on the urinary bladder mucosa. This interaction is critical for the ability of UPEC to colonize and invade the bladder epithelium. X-ray structures of FimH co-crystallized with the physiological binding epitope oligomannose-3 [2] and the antagonist biphenyl $\alpha$-D-mannoside 1 [3] revealed two different binding modes, an inand an out-docking-mode, respectively. To accomplish the in-docking-mode, the antagonists $\mathbf{2 - 5}$ with increased flexibility were designed and synthesized.

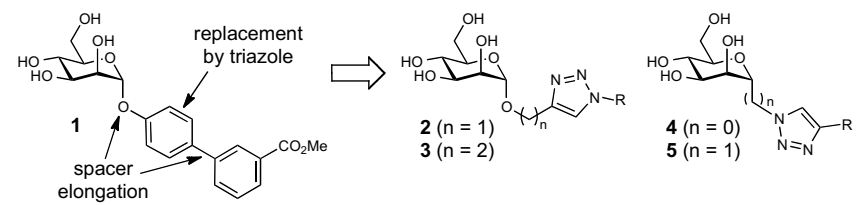

All triazoles 2-4 exhibit nanomolar affinities. A conformational analysis by NMR revealed that the comparably lower affinity of the $C$-mannosides 5 results from an unusual ${ }^{1} C_{4}$ chair conformation. Since orally available antagonists are aimed, selected pharmacokinetic parameters were determined.

[1] S. D. Fihn, N. Engl.J. Med. 2003, 349, 259.

[2] A. Wellens et al., PLoS ONE 2008, 3, 4.

[3] Z. Han et al., J. Med. Chem. 2010, 53, 4779.

Medicinal Chemistry

MC 11

\section{In A Search of Fluorinated PET Tracers for Imaging of mGluR5}

Selena Milicevic Sephton, Patrick Dennler, Stefanie D. Krämer, Roger Schibli, Simon M. Ametamey*

Center for Radiopharmaceutical Sciences, ETH Zurich, Wolfgang-Pauli Strasse 10, 8093 Zurich, Switzerland

Development of ${ }^{18} \mathrm{~F}$-labeled PET tracers for imaging of mGluR5 in the brain has been a long standing goal and several compounds have previously been explored but each demonstrated only limited success. The Ametamey group has recently developed an ${ }^{18} \mathrm{~F}$-labeled FDEGPECO tracer based on the structure of ABP688 [1]. ${ }^{18} \mathrm{~F}$-FDEGPECO showed excellent in vitro and good in vivo properties, however, brain radio-activity uptake was not optimal, thus limiting its possible application in human clinical practice [2].

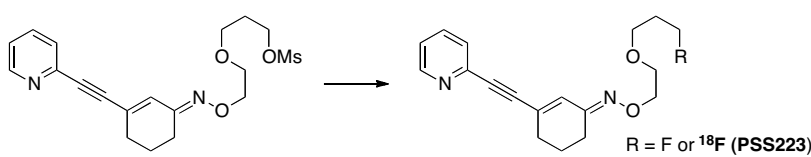

To accommodate the required higher lipophilicity, revision of the FDEGPECO structural motif was made and a novel derivative, PSS223, was synthesized in seven linear steps with overall 13\% yield. PSS223 exhibited nanomolar affinity $\left(\mathrm{K}_{i}=6 \mathrm{nM}\right)$ for mGluR5 in in vitro binding assays. Precursor for fluorine-18 radiolabeling was next prepared and the radiosynthesis was accomplished in good radiochemical yields. These results as well as the further in vitro and in vivo evaluation of ${ }^{18} \mathbf{F}$-PSS223 will be discussed.

[1] C. A. Baumann, L. Mu, S. Johannsen, M. Honer, P. A. Schubiger, S. M. Ametamey, J. Med. Chem. 2010, 53, 4009.

[2] C. A. Wanger-Baumann, M. Lu, M. Honer, S. Belli, M. F. Alf, P. A. Schibiger, S. D. Kraemer, S. M. Ametamey, Neuroimage, 2011, DOI:10.1016/j.neuroimage.2011.03.024.

\section{In Vitro and In Vivo evaluation of Squaric Acid Derivatives as FimH Antagonists}

Daniela Abgottspon, Oliver Schwardt, Simon Kleeb, Meike Scharenberg, Said Rabbani, Beat Ernst*

Institute of Molecular Pharmacy, University of Basel Klingelbergstrasse 50, CH-4056 Basel, Switzerland

Urinary tract infection (UTI) caused by uropathogenic Escherichia coli (UPEC) is one of the most common infections, affecting millions of people each year. $\alpha$-D-Mannopyranosides are potent FimH antagonists, inhibiting the adhesion of $E$. coli to high mannosylated uroplakin Ia on the urothelium. This mechanism offers a therapeutic opportunity for treatment and prevention of UTI and represents an alternative to antibiotics. We describe the synthesis as well as the in vitro and in vivo evaluation of squaric acid derivatives as FimH antagonists. For the evaluation of the in vitro activity, two different assays were applied, a target-based binding assay and a cell-based flow cytometry assay. The pharmacokinetic (PK) properties of the FimH antagonists ( $\mathrm{p} K_{\mathrm{a}}$, lipophilicity, solubility, gastrointestinal fluid stability, membrane permeation and plasma protein binding) were determined to predict their in vivo behaviour. The in vivo PK and efficacy studies were performed in the UTI mouse model. The squaric acid derivatives showed high in vitro activity. In vivo $\mathrm{PK}$ studies with one derivative exhibited a high availability at the target organs (bladder and kidneys) after i.v. injection, leading to a successful reducion of bacterial infection. The in vivo efficacy is comparable to standard antibiotic treatment used in the clinic, indicating the therapeutic potential of glycomimetics for treatment of UTI.

Medicinal Chemistry

MC 12

\section{Modulators of Human Stem Cell Fate in the Context of Regenerative Medicine}

Anthony E. Boitano ${ }^{1}$, Laure C. Bouchez ${ }^{2}$, Russell Romeo ${ }^{1}$, Michael P. Cooke ${ }^{1}$, Peter G. Schultz

Genomics Institute of the Novartis Research Foundation San Diego, CA92121 (USA) $^{1}$. Novartis Institutes for BioMedical Research, CH-4002 Ba$\mathrm{sel}^{2}$. Department of Chemistry, The Scripps Research Institute La Jolla, CA92037 (USA) ${ }^{3}$

Identification of external signals involved in the regulation of hematopoietic stem cell (HSC) proliferation and differentiation will provide not only fundamental insights in basic biology but also new therapies for the treatment of cancer and other hematological diseases. Ex-vivo HSC expansion has been a subject of intense research for the past 20 years; however, identification of culture conditions that allow expansion and long-term hematopoietic reconstitution have remained elusive. Manipulation of signaling pathways using low molecular weight (LMW) compounds represents an alternative approach that can be exploited to regulate ex-vivo HSC expansion. We developed and performed an unbiased high-throughput screen for small molecules using primary human CD34+ HSCs. We successfully identified a novel class of compounds that facilitates ex-vivo expansion of HSCs. [1,2] A similar screen was carried out for small molecules and secreted proteins that affect erythrocyte maturation. We found that under specific culture conditions we can drive the differentiation of human stem progenitor cells (HSPCs) toward erythroid lineages independent of erythropoietin (Epo). [3] Ultimately, this new finding may allow the ex vivo production of blood cells for therapeutic use.

[1] A. E. Boitano et al. Science 2010, 329, 1345-1348.

[2] L. C. Bouchez et al. ChemBioChem. 2011, 12, 854-857.

[2] Manuscript in preparation. 


\section{1ß-HSD1 Inhibitors for Type II Diabetes and Beyond - The Metabolic Syndrome}

W. Neidhart, A. Mayweg, Bernd Kuhn, J. Ackermann, D. Hunziker, A. Ruf, M. Otteneder, A. Luehe, E. Tozzo, P. Verry \& K. Amrein

$$
\text { F. Hoffmann-La Roche Ltd, CH-4070 Basel, Switzerland }
$$

$11 \beta$-Hydroxysteroid dehydrogenase type 1 (11 $\beta$-HSD1) is an endoplasmic reticulum-associated enzyme that acts as an NADPH-dependent reductase and converts inactive cortisone to the active glucocorticoid (GC), cortisol.

As such, it is a regulator of intracellular cortisol concentration and has been implicated in a number of metabolic disorders of increased glucocorticoid tone: visceral adiposity, high blood pressure, glucose intolerance and dyslipidemia, a cluster of cardiovascular risk factors defined as metabolic syndrome. Features of metabolic syndrome resemble the clinical picture of patients with increased plasma GC levels or Cushing's syndrome. The enzyme is expressed in most tissue, particularly in adipose tissue and liver. There is evidence from studies with transgenic animals that metabolic syndrome may result from increased intracellular glucocorticoid levels in liver \& adipose tissues and that pharmacological inhibition of $11 \beta$-HSD1 may normalize intracellular GC levels and be of therapeutic value for the treatment of type II diabetes \& metabolic syndrome.

In the effort towards novel, potent and selective 11 $\beta$-HSD1 inhibitors, a new class of functionalized N-heterocycles was identified and optimized through molecular design and X-ray structural data. Key compounds showing high enzyme and cell potencies with IC50 and EC5O values in the low nanomolar range were evaluated in depth. In PK/PD studies in mice they inhibited enzyme activity after oral dosing and in relevant mouse models they were shown to ameliorate insulin resistance and dyslipidemia.

Conclusion: It was demonstrated that pharmacological inhibition of $11 \beta$ HSD1 can improve features of the metabolic syndrome.

\section{Medicinal Chemistry}

MC 15

\section{Development of multivalent ligands for the detection of early stage cancers}

\author{
Solène Passemard ${ }^{1}$, Davide Staedler ${ }^{1,2}$, Damien Evéquoz ${ }^{1}$, Sandrine Gerber ${ }^{1}$
} and Lucienne Juillerat-Jeanneret ${ }^{2}$

\section{${ }^{1}$ ISIC, BCH, Ecole Polytechnique Fédérale de Lausanne, CH-1015 Lausan- ne, Switzerland \\ ${ }^{2}$ University Institute of Pathology, CHUV, CH-1011 Lausanne, Switzerland}

Medical imaging is a major tool for the prevention and the detection of cancer. The development of nanotechnology-based medical diagnostic tools could provide a qualitatively new level of sensitivity and accuracy for the detection of malignant diseases ${ }^{1}$. Here, the synthesis of functionalized nanomaterials with small targeting molecules that can capture cell entities for the detection of breast, lung and prostate cancers has been investigated (Scheme 1) ${ }^{2}$.

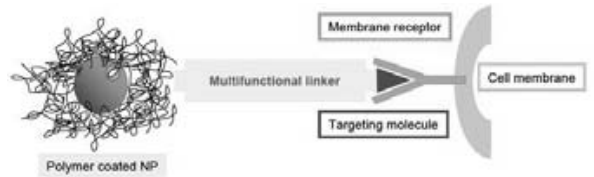

Scheme 1: Principle of targeting specific cells with nanoparticles

Multivalent ligands for both the specific targeting of breast cancer biomarkers and the conjugation to imaging probes was synthesized, which included selectively modified RGD, Erlotinib, Lapatinib, and an inhibitor for FAP in view of their conjugation to imaging nanoparticles. Biological evaluation of these scaffolds using human breast cancer cells demonstrated the high potential of these modified ligands-scaffolds to bind selectively to breast cancer cells.

${ }^{1}$ Dave, S.R.; Gao, X.; WIRES Nanomed. Nanobiotech, 2009, 1, 583-609.

2 This work was supported by the European Commission FP7

NAMDIATREAM project (EU NMP4-LA-2010-246479) and by the Interreg Program (Project NAOMI).
NMR investigation of the cellular targets and mechanistic profiles of ruthenium-hexacationic cages

\section{$\underline{\text { Lydia PAUL }}^{\mathrm{a}}$, Bruno THERRIEN $^{\mathrm{b}}$, Julien FURRER ${ }^{\mathrm{a}}$}

a Departement of Chemistry and Biochemistry, University of Berne, Freiestrasse 3, 3008 Berne.

${ }^{\mathrm{b}}$ Institut de Chimie, University of Neuchatel, rue Emile Argand 11, 2009, Neuchâtel.

Recently it was shown that ruthenium complexes possess several favorable chemical properties, suggesting that they may be strong candidates to replace platinum drugs and to form a basis for anti-cancer drug design. [1] We and other groups have synthesized a number of water-soluble hexanuclear metalla-prisms that form hexacationic cages. Their cavities can be used to encapsulate various guest molecules permanently or reversibly, and can be used as "Trojan Horses" to deliver drugs once inside cancer cells. $[2,3]$ However, in these systems the mode of action, uptake, release of the guest and the other biological processes remain poorly understood. In this contribution, we present our first results using an empty hydroxybenzoquinonato bridged ruthenium-prism as a model system, since its cytotoxicity has been evaluated as anticancer agent against A2780 human ovarian cancer cells.[3] The interactions between this cage and simple biomolecules such as amino acids, nucleotides, DNA strands, and glutathione have been investigated and monitored by NMR spectroscopy. The results presented provide a first insight into the identification of the ultimate cellular targets in cancer cells and blood plasma.

\section{References:}

[1] M. J. Clarke, F. Zhu, D. R. Frasca, Chem. Rev., 1999, 99, 2511

[2] B. Therrien, G. Süss-Fink, P. Govindaswamy, A. K. Renfrew, P. J. Dyson, Angew. Chem. Int. Ed., 2008, 47, 3773.

[3] O. Zava, J. Mattsson, B. Therrien, P.J. Dyson, Chem. Eur. J., 2010, 16, 1428 .

\section{Medicinal Chemistry}

MC 16

Functionalization of foetal osteoblasts for the development of bone implant

Françoise Borcard, ${ }^{1}$ Aurélien Godinat, ${ }^{1}$ Davide Staedler, ${ }^{1}$ Horacio Comas, ${ }^{1}$ Franziska Krauss Juillerat, ${ }^{2}$ Sandrine Gerber-Lemaire, ${ }^{1}$ Lucienne JuilleratJeanneret $^{3}$ and Urs Gonzenbach ${ }^{2}$

${ }^{1}$ ISIC, BCH, EPFL, CH-1015 Lausanne, Switzerland, ${ }^{2}$ Department of Materials, ETH-Zürich, Zürich, Switzerland, ${ }^{3}$ University Institute of Pathology, CHUV, Lausanne, Switzerland

Tissue engineering represents a promising approach for the treatment of large bone defects, in which biomaterials are seeded with cells that are expected to promote bone reconstruction.

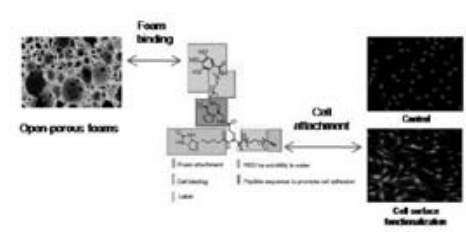

This project aims at the synthesis of multifunctional linkers designed to covalently link both particle-stabilized ceramic foams with defined pore structures [1] and cells. Here we present the synthesis of a chemical linker containing specific entities for cell surface functionalization, attachment to biomaterial and cell adhesion promotion [2]. Cell surface functionalization by biocompatible copper promoted click reaction [4] and copper free click reaction [3] is also introduced and demonstrated the potential for bone implant development [5].

[1] Krauss Juillerat, F.; Gonzenbach, U. T.; Studart, A. R.; Gauckler, L. J. Mat. Lett. 2010 64, 1468-1470. [2] Krauss Juillerat, F.; Scaletta, C.; Applegate. L. A.; Borcard, F.; Comas, H.; Gauckler, L. J., Gerber-Lemaire, S; Juillerat-Jeanneret, L.; Gonzenbach, U.,submitted. [3] Bertozzi, C. R. et al. J. Am. Chem. Soc 2010, 130, 11486-11493. [4] Hong, et al. Bioconjugate Chem. 2010, 21, 1912-1916. [5] Borcard, F.; Godinat, A.; Staedler, D.; Comas, H.; Dumont, A. L.; Chapuis-Bernasconi, C.;Scaletta, C.; Applegate, L. A.; Krauss-Juillerat, F.; Gonzenbach, U.; Gerber-Lemaire, S.; Juillerat-Jeanneret, L., submitted 
Medicinal Chemistry

\section{Characterization of a Novel Antimalarial Chemotype}

${ }^{1)}$ Bibia Heidmann, ${ }^{1)}$ Hamed Aissaoui, ${ }^{1)}$ Romain Siegrist, ${ }^{1)}$ Olivier Corminboeuf, ${ }^{11}$ Christoph Binkert, ${ }^{11}$ Solange Meyer, ${ }^{1)}$ Stephane Delahaye, ${ }^{1)}$ Amelie LeBihan, ${ }^{2}$ Ralf Brunner, ${ }^{2}$ Sergio Wittlin, ${ }^{2}$ Reto Brun and ${ }^{1)}$ Christoph Boss

${ }^{1)}$ Actelion Pharmaceuticals Ltd, Gewerbestrasse 16, CH-4123 Allschwil, Switzerland and ${ }^{2}$ Swiss Tropical and Public Health Institute (Swiss TPH), Socinstrasse 57, CH-4051 Basel, Switzerland

Malaria, caused by protozoan parasites of the genus Plasmodium is still a major health problem. Every year more than 240 millions of malaria cases are recorded. The disease accounts for about 1 million of lethal cases per year [1]. Malaria is responsible for $20 \%$ of children's deaths in sub-saharan Africa. The two main issues which prevent efficient malaria control in the most strongly affected regions are: too expensive medications and increasingly drug-resistant parasite strains. This clearly indicates the need for new drugs with novel modes of action. We will describe a representative of a new class of antimalarial agents which potently inhibits in vitro erythrocytic Plasmodium falciparum growth of all tested strains with $\mathrm{IC}_{50}$ values in the low single-digit nanomolar range, irrespective of their resistance properties. The compound exhibits oral bioavailability in mice and shows pharmacological efficacy in two mouse models of malaria. The mode of action seems to be different from known antimalarial compounds. First SAR investigations as well as our efforts on the broader characterization of the compound and its properties will be disclosed [2].

[1] K. Santwana, K. Santosh, Nat. Rev. Drug Disc. 2010, 9, 511.

[2] C. Binkert, C. Boss, O. Corminboeuf, C. Grisostomi, S. Meyer, WO2007/046075 (Actelion Pharmaceuticals Ltd).

\section{Medicinal Chemistry}

MC 19

New and unconventional approaches for tuning disulfide linkers for redox-sensitive drug delivery

Chuanliu Wu, Marc A. Gauthier, and Jean-Christophe Leroux

Department of Chemistry and Applied Biosciences, Institute of Pharmaceutical Sciences, Swiss Federal Institute of Technology Zürich (ETHZ), Wolfgang-Pauli Str. 10, HCI J 390, 8093 Zürich, Switzerland

Redox-sensitive drug delivery exploits endogenous reducing agents (glutathione or cysteine) to cleave disulfide bonds in a concentration-dependent manner with time. Using redox-sensitive linkers, such as disulfides, drug release can be achieved via cleavage of disulfide-linked prodrugs, or by destabilization of drug carriers (held together by disulfides) in which drugs are entrapped. In comparison to the other endogenous stimuli ( $\mathrm{pH}$, enzymes), the use of this stimulus is comparatively young and our understanding of the tunability of disulfides to control the rate and location of cleavage is, to a certain extent, limited.

In the first part of this contribution, we present a new, rational, predictable, and easily accessible means of altering the rate of cleavage of simple disulfides over $\sim 3$ orders of magnitude.

In the second part of this contribution, we present an unconventional yet accessible means of overcoming the duality of achieving disulfide linker stability in the blood while maintaining responsiveness (i.e., poor stability) at target locations.
Medicinal Chemistry

MC 18

\section{A model for substrate-binding in the bimetallic active site of the antimicrobial target $\mathrm{N}$-succinyl-L,L- diaminopimelic acid hydrolase (DapE)}

\author{
Upert, G., Uda, N., Creus, M.*
}

Department of Chemistry, University of Basel, Spitalstrasse 51, Basel CH4056, Switzerland

The emergence of bacterial strains that are resistant to virtually all currently available antibiotics underscores the importance of finding new targets for inhibition by antimicrobial compounds, while minimizing the risk of future resistance.

DapE ( $N$-succinyl-L,L-diaminopimelic acid desuccinylase $)$ is an essential metalloenzyme for Gram-negative and some Gram-positive bacteria which has been proposed as a good target for antibiotic development [1]. Here, we propose an alternative model for the binding of the substrate in the active site of dapE.

A deeper understanding of the catalytic site of DapE is expected to lead to improved design of antibiotics that inhibit cell-wall synthesis in bacteria.

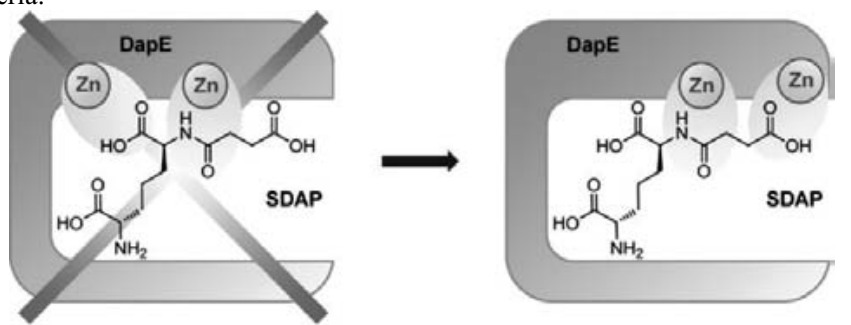

[1] Uda N., Creus M., Bioinorg Chem and Appl. 2011, Article ID 306465, 6 pages.

Medicinal Chemistry

MC 20

\section{$\mathrm{CyBy}^{2}$ : A modular Rich Client for the chemical and biological Information Management}

Stefan Höck, Rainer Riedl*

Zurich University of Applied Sciences, Institute of Chemistry and Biological Chemistry, Campus Reidbach, CH-8820 Wädenswil, Switzerland

Medicinal chemistry projects are very complex with respect to the chemical and biological data content. For successful medicinal chemistry projects, it is mandatory to have access to key correlations between chemical structures and their biological data such as potency, selectivity and pharmacological data to highlight and easily extrude structure activity relationships (SAR). The professional information management of a multitude of medicinal chemistry projects in a given organization such as pharmaceutical companies requires intelligent IT-tools to fully utilise the organization's global data.

We present a fully-fledged rich client application for the convenient storage and retrieval of chemical structures alongside the data of their biological activity in an underlying database that facilitates the structure-based data management and visualization of structure activity relationships (SAR). Written in Scala [1] and being based on Chemaxon's JChem [2] and the Netbeans Platform [3] the application is modular and thus easily expandable with additional functionality according to the individual user's needs.

[1] Martin Odersky, The Scala Language Specification, Version 2.8; Programming Methods Laboratory EPFL, Lausanne 2010.

[2] http://www.chemaxon.com/

[3] http://netbeans.org/ 


\section{Antimalarial activity of nostocarboline and analogues}

\section{Srboljub Vujovic, Karl Gademann}

University of Basel, St. Johanns-Ring 19, CH-4056 Basel, Switzerland

Nostocarboline $\mathbf{1}$ is a quaternary $\beta$-carboline alkaloid isolated from the freshwater cyanobacterium Nostoc 78-12A [1]. It has has been shown to display potent and selective inhibition of the malaria parasite Plasmodium falciparum at submicromolar concentration [2].<smiles></smiles>

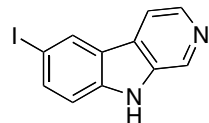

4

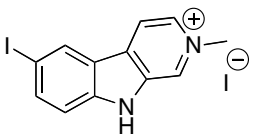

2

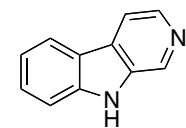

3
Its iodinated analogue 2 at the 6 position has been prepared by iodination and methylation of norharmane 3. Subsequent reaction of 6-I-norharmane 4 with various boronic acids using the Suzuki-Miyaura cross-coupling followed by methylation allowed the synthesis of numerous derivatives $\mathbf{5}$. Those new compounds as well as $\mathbf{2}$ have been tested for their antimalarial activity.

[1] P. G. Becher, J. Beuchat, K. Gademann, F. Jüttner, J. Nat. Prod. 2005 , $68,1793$.

[2] S. Bonazzi, D. Barbaras, L. Patiny, R. Scopelliti, P. Schneider, S. T. Cole, M. Kaiser. R. Brun, K. Gademann, Bioorg. Med. Chem. 2010, 18, 1464 .

\section{Medicinal Chemistry}

MC 23

\section{Synthesis of high affinity fluorescent probes to study the $5-\mathrm{HT}_{3}$ receptor}

\section{Jonathan Simonin $^{1}$ and Martin Lochner ${ }^{1}$ \\ ${ }^{1}$ Universität Bern, Department of Chemistry and Biochemistry, CH-3012} Bern, Switzerland

The 5- $\mathrm{HT}_{3}$ receptor is a ligand-gated ion channel (LGIC) and a member of the Cys-loop family of receptors. Antagonists of the 5-HT 3 receptor (e.g. granisetron) are widely used clinically for the treatement of emesis and irritable bowel syndrome.[1] Based on our SAR study of granisetron we used its core to attach fluorophores like coumarin, fluorescein or rhodamine $\mathrm{B}$ at two different positions, with different linkers varying in length and solubility properties. [2] The fluorescent ligands have been characterised by radioligand binding $\left(\mathrm{K}_{\mathrm{i}}\right)$ and fluorescence spectroscopy. The aim of this work is to discover fluorescent ligands of type 2-7 that bind with high affinity to the $5-\mathrm{HT}_{3}$ receptor and show a high fluorescence polarization over background when bound.

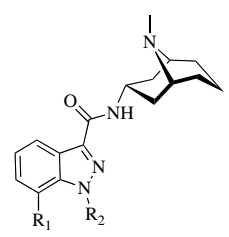

$$
\begin{aligned}
& \text { 1: } \mathrm{R} 1=\mathrm{H}, \mathrm{R} 2=\mathrm{Me}: \text { Granisetron } \\
& \text { 2,3: } \mathrm{R} 1= \\
& \text { 7: } \mathrm{R} 1=\mathrm{R} 1=\mathrm{H}, \mathrm{R} 2=\mathrm{H}, \mathrm{R} 2=
\end{aligned}
$$$$
\text { 4: } \mathrm{R} 1=\stackrel{\mathrm{O}}{\mathrm{N}} \mathrm{O}_{2} \mathrm{~N}_{\mathrm{H}}^{-}-\mathrm{R}_{3}, \mathrm{R} 2=\mathrm{Me} \quad \begin{aligned}
& \mathrm{R} 3=\text { coumarin, fluorescein or } \\
& \text { rhodamine } \mathrm{B}
\end{aligned}
$$

[1] A.J. Thompson; S.C.R. Lummis. Expert Opin. Ther. Targets $2007 ; 11,527$

[2] S.K.V.Vernekar; H.Y. Hallaq; G.Clarkson; A.J.Thompson; L.Silvestri; S.C.R.Lummis M.Lochner, J. Med. Chem., 2010, 53, 2324
BZM055, a SPECT tracer candidate for studying FTY720 brain distribution and myelin imaging

Emanuele Mauro, Emmanuelle Briard, Orain David, Christian Beerli, Andreas Billich, Markus Streiff, Marc Bigaud, Yves P. Auberson

Novartis Institutes for BioMedical Research, Novartis Pharma AG, Postfach, CH-4002 Basel, Switzerland

FTY720 (fingolimod, Gilenia ${ }^{\circledR}$ ) is a sphingosine 1-phosphate (S1P) receptor modulator that showed significant improvement in relapse rate after oral administration to multiple sclerosis (MS) patients.[1] We propose here an imaging tracer to study the pharmacokinetics and organ distribution of FTY720 in patients and, since this drug accumulates in myelin sheaths, for myelin imaging.

FTY720 does not contain any atom whose Positron Emission Tomography (PET) or Single Photon Emission Computed Tomography (SPECT) radioisotope would have a half-life compatible with its pharmacokinetic properties. With this in mind, we defined the criteria that would make a radiolabeled derivative of FTY720 an adequate surrogate of the drug, mimicking its pharmacokinetics and organ distribution, but also its affinity, selectivity for $\mathrm{S} 1 \mathrm{P}$ receptors and phosphorylation rate, as well as having similar overall physicochemical properties.

From all candidate tracers profiled according to these criteria, we selected BZM055 for PET/SPECT radiolabeling and further characterization, as it is the closest mimic of the drug. [2] Its synthesis and profile is described in the poster.

[1] L. Kappos et al. N. Engl. J. Med. 2010, 362(5), 387

[2] E. Briard et al. ChemMedChem, 2011, 667-677

Medicinal Chemistry

MC 24

Lactam and 4'-Deoxy Analogs of Resorcylic Acid Lactone L-783277: Synthesis and SAR Studies

Michel R. Jordi, Marc Liniger, Christian M. Neuhaus, Karl-Heinz Altmann*

ETH Zürich, Institute of Pharmaceutical Sciences, HCI,

Wolfgang-Pauli-Str. 10, CH-8093 Zürich, Switzerland

Resorcylic acid lactones (RALs) are mycotoxins produced by a variety of different fungal strains, of which those containing a cis-enone moiety have been reported to be potent, irreversible kinase inhibitors, ${ }^{[1]}$ including L$783277(1) .{ }^{[2]}$ The cis-enone moiety is essential for activity, as it acts as a Michael acceptor for a Cys residue present in the ATP-binding pocket of a subset of kinases. We have previously reported the first total synthesis of L783277 (1) ${ }^{[3]}$ and we have also shown that 5'-deoxy-L-783277 (2) retains almost the full kinase inhibitory activity of $\mathbf{1}^{[4]}$
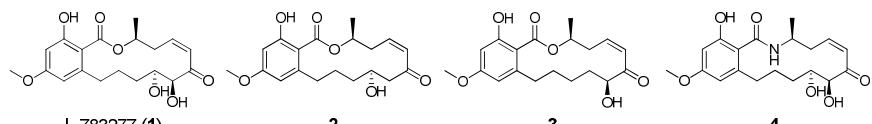

L-783277 (1)

Those previous studies left open the question of the activity of the 4'-deoxy analog 3, which could not be accessed according to our original synthetic strategy. We have now overcome these difficulties and we have produced $\mathbf{3}$ in sufficient quantities for biological studies. As part of our ongoing SAR studies on 1 we have also addressed the activity of lactam analog 4 , which we expect to be metabolically more stable than the parent macrolactone. In this contribution we report on the details of the syntheses of $\mathbf{3}$ and $\mathbf{4}$ and the kinase inhibition profile of these new L-783277 analogs.

[1] Hofmann, T.; Altmann, K.-H., Compt. Rend. 2008, 11, 1318.

[2] Zhao, A. et al., J. Antibiot. 1999, 52, 1086.

[3] Hofmann, T.; Altmann, K.-H., Synlett 2008, 10,1500.

[4] Liniger, M. et al., ACS Med. Chem. Lett.2011, 2, 22. 
Title Influence of surface charge on protein adsorption on polymer coated iron oxide nanoparticles

Fink Alke, Salaklang Jatuporn, Hirsch Vera

Université de Fribourg, Chemin du Musée 9, 1700 Fribourg, Switzerland

Nanoparticles in a biological fluid associate with a range of biopolymers, especially proteins, and it is hypothesized that cellular responses to this materials reflect the adsorbed biomolecule layer, rather than the material itself $[1,2]$. In case of systemically applied particles the adsorption patterns are regarded as the key factor for the particles in vivo organ distribution. In this study the effects of different surface charges of polymer coated superparamagnetic iron oxide nanoparticles (SPIONs) on the protein adsorption are investigated.

A range of polymer coated magnetic nanoparticles with different surface charges (positive, negative and neutral) were synthesized and their physicochemical parameters were determined in terms of size and zeta-potential. After incubation with fetal bovine serum, sodium gel electrophoresis was employed to detect the proteins eluted from the particles followed peptide detection with mass spectrometry (MS).

The obtained results show that the adsorption patters differ considerably by only varying one parameter (the charge).

As the applications of SPIONs in biomedicine have drastically increased in recent years $[3,4]$, this knowledge is important for the perspective of safe use of nanomaterials as it can be exploited for future controlled design of advanced particle systems for medical purposes.

Future questions to be answered concern adsorption kinetic studies (e.g. ITC) and protein profiling in environments of higher complexity (e.g. cells).

[1] I. Lynch et al., Science STKE, 2006, 14, 327

[2] L.T.Allen et al., Biomaterials, 2006, 27, 3096

[3] C.C. Berry et al., J. Phys. D, Appl. Pys., 2003, 36, 198

[4] S. Laurent et al., Chem Rev., 2008, 108, 2064

Medicinal Chemistry

MC 27

\section{Vitamin B12 as a carrier for $\mathrm{Ru}(\mathrm{II})$-arene anticancer drugs}

\section{Mai Thanh Quynh Tran, Roger Alberto}

Institute of Inorganic Chemistry - University of Zurich,

Winterthurerstrasse 190, CH-8057 Zurich, Switzerland

Since vitamin B12 is essential for fast growing cells such as cancer cells, it has been an inspiration for the targeted delivery of metallo-drugs. The crystal structure of vitamin $\mathrm{B} 12-\left\{\mathrm{PtCl}\left(\mathrm{NH}_{3}\right)_{2}\right\}$ conjugate (1) was reported previously. Compound (1) is stable under physiological conditions for more than 24 hours. ${ }^{[1 \mathrm{a}]}$ It is recognized by intracellular enzymes and converted to coenzyme B12. ${ }^{[1 \mathrm{~b}]}$ Despite the fact that (1) showed lower cytotoxicity than cisplatin itself, the cleaved Pt-species exhibited comparable cytotoxicity to that of cisplatin. ${ }^{[1 \mathrm{c}]}$ This work studied the possibility of vitamin B12 to carry another promising anticancer agent, ruthenium (II) arene drugs. ${ }^{[2]}$ The vitamin $\mathrm{B} 12-\{\mathrm{Ru}(\mathrm{II})(\mathrm{ar})(\mathrm{en})\}$ conjugate (2) was synthesized. Under physiological conditions, $30 \%$ and $50 \%$ of the $\{\mathrm{Ru}(\mathrm{II})(\mathrm{ar})(\mathrm{en})\}$ was cleaved from vitamin B12 after 24 and 48 hours, respectively. The reduction of (2) lead to the formation of aquocobalamin hinting that the cleaved species is actually $\{\mathrm{Ru}(\mathrm{II})(\mathrm{ar})(\mathrm{en}) \mathrm{CN}\}$. Further biological studies of (2) are currently under way.

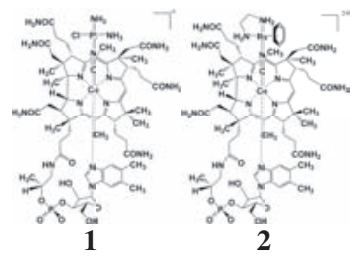

[1] a) S. Mundwiler et al., Chem. Eur. J., 2005, 11, 4089. b) P. R. Sanchéz et al., J. Biol. Inorg. Chem., 2008, 13, 335. c) P. R. Sanchéz et al., J. Biol. Inorg. Chem., 2011, 16, 33.

[2] A. Habtemariam et al., J. Med.Chem., 2006, 49, 6858.
Pyrazine Indazoles as Inhibitors of T Cell Activation: From PKB/Akt to selective PKC Inhibitors

Rudolf Duthaler, Samuel Hintermann, Sandra Jacob, Bernard Pirard, Gabriele Rummel, Walter Schuler, Gebhard Thoma, Anette von Matt, Peter von Matt, Nina Gommermann

ATI and Global Discovery Chemistry, Novartis Institutes for BioMedical Research, Postfach, 4002 Basel, Switzerland

Combined inhibition of both classical and novel protein kinase $\mathrm{C}$ (PKC) isoforms has been shown to lead to potent blockage of T-cell activation, resulting in immunosuppresion. Therefore, the search for novel chemotypes acting as panPKC inhibitors is of high importance.

Using the known protein kinase $\mathrm{B}$ (PKB) inhibitor $\mathbf{1}$ as a chemical starting point, ${ }^{1}$ we could succesfully dial out the unwanted PKB activity during the hit to lead optimisation. The activity on the classical PKC isoforms could also be improved, keeping a good selectivity window against PKB.

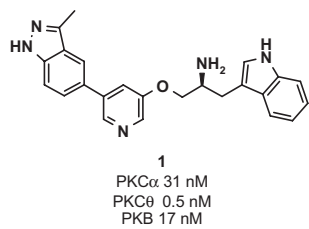

This short talk describes the medicinal chemistry program that led to the discovery of the pyrazine indazole series of panPKC inhibitors guided by protein structure aided drug design.

[1] K. W. Woods et al. Bioorg. Med. Chem. 2006, 14, 6832; WO2003/051366.

Medicinal Chemistry

MC 28

Isolation and characterization of DYRK1A and CLK1 inhibitors from plant extracts

Patrick Grabher ${ }^{1}$, Laurent Meijer ${ }^{2}$, Matthias Hamburger ${ }^{1}$, Olivier Potterat ${ }^{1 *}$

${ }^{1}$ Pharmaceutical Biology, University of Basel, Klingelbergstrasse 50, CH-4056 Basel, Switzerland

${ }^{2}$ Station Biologique de Roscoff, Cell Cycle Group, CNRS, F-29682 Roscoff, France

The dual specificity kinase DYRK1A possesses diverse roles in neuronal development and adult brain physiology, and increased activity has been linked to neurodegenerative diseases [1]. Very few inhibitors of this kinase have been reported up to now.

Screening of a library of $>900$ plant and fungal extracts afforded 26 extracts with $\mathrm{IC}_{50} \mathrm{~S}<6.2 \mu \mathrm{g} / \mathrm{ml}$ against DYRK1A. To identify the active constituents, the extracts were submitted to a process integrating physicochemical data with biological information, referred to a HPLC-based activity profiling. Follow-up investigation of three extracts led to the targeted isolation of harmine from Peganum harmala, kaempferol and kaempferol-3-O- $\beta$-Dgalactopyranoside from Cuscuta chinensis, 3,7-dimethylherbacetin, 3,8dimethylherbacetin, 3,3',4'-trimethylmyricetin and ombuin from Larrea tridentata as the active constituents. Active extracts and compounds were also tested on the closely related kinase CLK1. Harmine and kaempferol show moderate selectivity for DYRK1 with selectivity factors of 4.8 and 3.8 , respectively. The results demonstrate the potential of natural product extracts and HPLC-based activity profiling for the discovery of new DYRK1A inhibitors.

[1] J. Wegiel, C.X. Gong, Y.W. Hwang, FEBS Journal 2011, 278, 236 
Medicinal Chemistry

Computational Study of the Enzymatic Reaction Mechanism in Dengue Methyltransferase

Tobias Schmidt ${ }^{\dagger \star}$, Torsten Schwede ${ }^{\dagger}$, Markus Meuwly ${ }^{\star}$

${ }^{\dagger}$ Swiss Institute of Bioinformatics, Biozentrum, University of Basel, Klingelbergstrasse 50/70, CH-4056 Basel, Switzerland

${ }^{\star}$ Department of Chemistry, University of Basel, Klingelbergstrasse 80, CH-4056 Basel, Switzerland

Dengue fever is a mosquito-borne viral infectious disease predominantly prevalent in tropical regions with annually 50-100 million cases and around 25000 death worldwide. The desease is caused by a positive-sense RNA virus. Currently, neither vaccines nor specific drug treatments are available.[1]

The dengue virus genome contains a type 1 cap structure at its 5' end which is essential for viral replication.[2] The viral NS5 RNA methyltransferase is critical for the formation of the RNA cap structure and is thus an attractive target for drug discovery.[3-5] Despite this fact, little is known about the mechanism underlying its function. The enzyme is known to catalyze two distinct reactions on an RNA cap structure with a specific sequence,[4] but so far neither the structure nor the mechanism of the two methylation reactions is known at an atomistic level.

Thus, we have built structural models of the protein in complex with the RNA and applied molecular dynamics simulations to understand the RNA sequence specificity of the enzyme. Thereby we identified protein residues critical for RNA sequence specificity. Furthermore, we investigate possible reaction pathways at an atomistic level, using high level $\mathrm{ab}$ initio calculations and were thereby able to further characterize the catalyzed reactions.

[1] D.J. Gubler, Novartis Found. Symp., 2006, 277, 3.

[2] G.R. Cleaves et al., Virology, 1979, 96, 159.

[3] M.P. Egloff et al., Embo Journal, 2002, 21, 2757.

[4] H. Dong et al. Antiviral Res., 2008, 80, 1.

[5] M. Podvinec et al., J. Med. Chem., 2010, 53, 1483.

Medicinal Chemistry

MC 31

Dendrimers Encapsulated in Metalla-Cages: Biological Applications.

Anaïs Pitto-Barry, Nicolas P. E. Barry, Olivier Zava, Paul J. Dyson, Robert Deschenaux, Bruno Therrien

University of Neuchâtel, Ave de Bellevaux 51, 2000 Neuchâtel, Switzerland

Dendrimers have recently been of central interest as biological agents. ${ }^{1}$ On the other hand, improvement of the anticancer activities of guest molecules after encapsulation in arene ruthenium metalla-prisms has been established. ${ }^{2}$

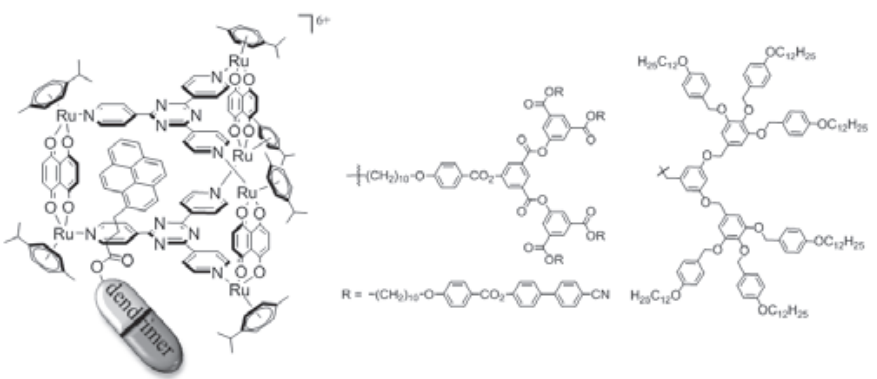

The combination of the behavior of two types of dendrimers with the biological activity of a metalla-prim will be presented. ${ }^{3}$ The host-guest properties and the stability in solution of the host-guest systems, as well as their cytotoxicity and selectivity on human ovarian cancer cell lines will be discussed.

[1] M. A. Mintzer, M. W. Grinstaff, Chem. Soc. Rev. 2011, 40, 173.

[2] B. Therrien, G. Süss-Fink, P. Govindaswamy, A. K. Renfrew, P. J. Dyson, Angew. Chem. Int. Ed. 2008, 47, 3773

[3] A. Pitto-Barry, N. P. E. Barry, O. Zava, R. Deschenaux, P. J. Dyson, B. Therrien, Chem. Eur. J. 2011, 17, 1966.
Medicinal Chemistry

MC 30

Fragment based design and synthesis of novel MMP inhibitors

Thomas Fischer, Michael Brand, Patrik Züger, Rainer Riedl*

Zurich University of Applied Sciences, Institute of Chemistry and Biological Chemistry, Campus Reidbach, CH-8820 Wädenswil, Switzerland

The human matrix metalloproteinases (MMPs) are zinc proteases with essential roles in breaking down components of the extracellular matrix (ECM). Additional MMP substrates include cytokines, chemokines, growth factors, cell/cell adhesion molecules, and other proteinases. An over activity of MMPs can lead to various pathological processes such as rheumatoid arthritis or tumor growth and metastasis for example [1].

There is a need for potent and selective MMP inhibitors, given the relevance of this class of enzymes in a multitude of pathogenic processes.

We have established a solid process for the development of novel scaffolds of MMP inhibitors. The process consists of the fragment based design [2] of novel scaffolds in silico using our massive database of fragments, subsequent docking and filtering according to medicinal chemistry rules, synthesis of the final compounds and the biological assays.

[1] M. Natchus J.Med.Chem. 2001, 44, 1060-1071.

[2] P. Hajduk, J. Greer Nature Reviews Drug Discovery 2007, 6, 211-219.

Medicinal Chemistry

MC 32

\section{Arene Ruthenium Metalla-Cages and Biological Applications}

Nicolas Barry, Bruno Therrien

Université de Neuchâtel, 51 Ave de Bellevaux, 2000, Neuchâtel, Suisse.

Coordination-driven self-assembly allows a directional-bonding approach that organises the different building blocks leading to the straightforward construction of large and rigid supramolecular objects with well-defined shapes, sizes and geometries, such as metalla-rectangles and metallaprisms. ${ }^{[1]}$ These complexes possess cavities in which permanent or temporary encapsulations of guest molecules are possible. These guest molecules can be organic, organometallic or inorganic molecules. ${ }^{[2]}$

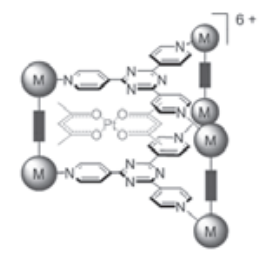

complex-in-a-complex
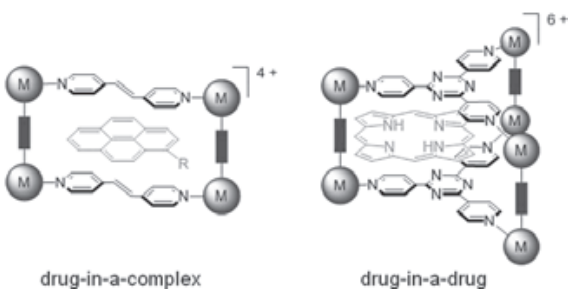

In recent years, we have been working on such large metalla-assemblies built by coordination-driven self-assembly. The improvements of the antiproliferative activities of organic and organometallic guest molecules after encapsulation have been established. ${ }^{3}$ The newest results will be the focus of this poster.

[1] S. Leininger, B. Olenyuk, P. J. Stang, Chem. Rev., 2000, 853.

[2] B. Therrien, Eur. J. Inorg. Chem., 2009, 2445.

[3] B. Therrien, G. Süss-Fink, P. Govindaswamy, A. K. Renfrew, P. J. Dyson, Angew. Chem. Int. Ed., 2008, 47, 3773. 
Synthesis of photoaffinity probes for the site-selective chemical modifications of the $5-\mathrm{HT}_{3}$ receptor

Thomas Jack and Martin Lochner

University of Bern, DCB, Freietrasse 3, CH-3012 Bern

The $5-\mathrm{HT}_{3}$ receptor $\left(5-\mathrm{HT}_{3} \mathrm{R}\right)$ is an important ion channel responsible for the transmission of nerve impulses in the central nervous system. ${ }^{[1]}$ It is difficult to characterize membrane bound receptors with classic approaches like crystallization and x-ray. The use of photoaffinity probes is an alternative approach to identify regions in the protein that are important for the binding of small molecules. Therefore we synthesized a small library of tagging molecules by combining a photolabile building block over various linkers to Gransietron that shows high affinity towards the $5-\mathrm{HT}_{3} \mathrm{R}$. Granisetron is a high potent antagonist that tolerates several chemical modifications without losing affinity. ${ }^{[2]}$ The conjugation of a trifluoromethyl-diazirin photolabile moiety with Granisetron leads to a molecule with potentially selective binding properties and, after irradiation, the ability to covalently attach to the $5-\mathrm{HT}_{3} \mathrm{R}$. The analysis of the covalently modified receptor will be purpose of further studies.

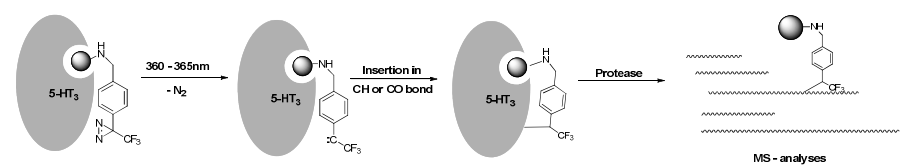

[1] Reeves D.C.; Lummis S.C.R., Mol. Membr. Biol. 2002, 19, 11.

[2] Vernekar S.K., Hallaq H.Y., Clarkson G., Thompson A.J., Silvestri L., Lummis S.C., Lochner M., J. Med. Chem. 2010, 53, 2324-2328
MC 35

\section{NMR studies on photosensitizers and metal-based photosensitizers}

\section{Mattia Marzorati, Julien Furrer, Martina Vermathen}

Department of Chemistry and Biochemistry - NMR-Laboratory, University of Berne, Freiestrasse 3, 3012 Bern, Switzerland

Photosensitizers (PSs) are mainly porphyrin-based compounds which play a key role in Photodynamic therapy (PDT). [1] Current research is focused on finding new and more active PSs, in order to increase their efficacy in PDT. Metal-based PSs seem to be very attractive, as the presence of a central metal ion can strongly influence the phototoxic efficiency of a PS. [2]

To probe the importance of the metal ion, we have carried out a series of NMR studies aimed at comparing the behavior of 2 water soluble PSs, i.e. meso-tetra(4-sulfonatophenyl)porphine $\left(\mathrm{TPPS}_{4}\right) \quad(\mathbf{1})$ and phthalocyanine tetrasulfonic acid $\left(\mathrm{PcS}_{4}\right)(2)$ with 4 of their respective metal-based compounds: $\mathrm{Cu}(\mathrm{II})-\mathrm{TPPS}_{4}$ (1a), $\mathrm{Mn}(\mathrm{III})-\mathrm{TPPS}_{4}$ chloride (1b), $\mathrm{Zn}(\mathrm{II})-\mathrm{PcS}_{4}$ (2a) and $\mathrm{Al}(\mathrm{III})-\mathrm{PcS}_{4}$ chloride (2b). The applied NMR methods have proved to be a powerful tool in this field. [3]

The free base and metal complexes have been compared with respect to their aggregation behavior in water and their interactions with model membranes (micelles and vesicles), both crucial factors in PDT. The results indicate that the presence of the metal in the compounds is highly distinctive.
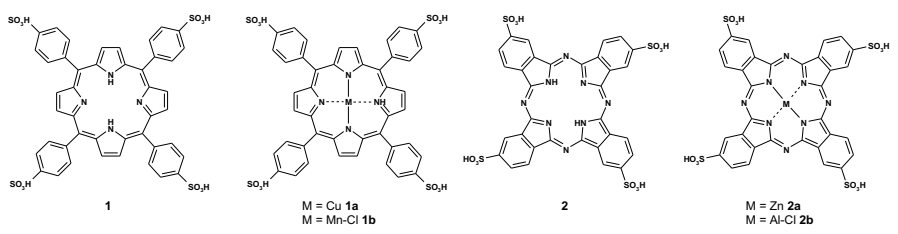

[1] Ethirajan M et al., Chem. Soc. Rev., 2011, 40, 340.

[2] Ali H. et al., Chem. Rev., 1999, 99, 2379.

[3] Marzorati M et al., Biochim. Biophys. Acta, 2011, 1808, 1661.

\section{Synthesis of tetracycline analogues}

\section{Michael Brand, Mark Sephton, Rainer Riedl*}

Zurich University of Applied Sciences, Institute of Chemistry and Biological Chemistry, Campus Reidbach, CH-8820 Wädenswil, Switzerland

Due to an ever increasing resistance to traditional antibiotic compounds, including those used as a last line of defense, such as Vancomycin, there are many efforts to discover new antibiotic substances [1]. An innovative approach to the resistance problem has recently been discovered [2], in which small organic compounds are used as co-treatments with antibiotics in which the bacteria are rendered susceptible to the original antibiotic and thus circumventing the perpetual need for new antibiotic compounds. To this end, we present the preparation of a concise library of small organic compounds by multistep organic syntheses [3] based on an active tetracycline derivative to probe the functionality and backbone requirements of the system.

[1] Chrast-Balz, J.; van Huijsdujnen, R. H. Nucleic Acids Research, 1996, 24, 2900-2904.

[2] Weber, W.; Schoenmakers, R.; Keller, B.; Gitzinger, M.; Grau, T.; Daoud-El Baba, M.; Sander, P.; Fussenegger, M. PNAS, 2008, 105, 9994-9998.

[3] Kerdesky, F. A.; Ardecky, R. J.; Lakshmikantham, M. V.; Cava, M. P. J. Am. Chem. Soc., 1981, 103, 1992-1996.
Medicinal Chemistry

MC 36

Discovery of $\alpha 7$-Nicotinic Receptor Ligands by Virtual Screening of the Chemical Universe Database GDB-13

Lorenz Blum, Ruud van Deursen, Sonia Bertrand, Justus Bürgi, Daniel Bertrand and Jean-Louis Reymond*

University of Berne, Dept. of Chemistry \& Biochemistry, Freiestr. 3, 3012 Berne, Switzerland

The Chemical Universe Database GDB-13 contains organic molecules with up to 13 atoms of $\mathrm{C}, \mathrm{N}, \mathrm{O}, \mathrm{Cl}$ and $\mathrm{S}$ following simple rules for chemical stability and synthetic feasibility. ${ }^{1}$

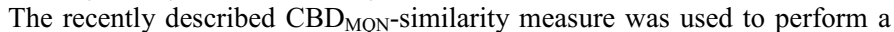
virtual screening in GDB-13 with nicotine as lead structure. ${ }^{2}$ Mining the GDB-13, the closest nicotine analogues were analyzed and selected compounds were purchased and tested for modulation of the acetylcholine signal at the human $\alpha 7$ nicotinic acetylcholine receptor (nAChR) expressed in Xenopus oocytes. Two unknown competitive inhibitors were identified and characterized. These experiments demonstrate for the first time the use of GDB-13 as a powerful ligand discovery tool.

[1] L. Blum, J.-L. Reymond, J. Am. Chem. Soc. 2009, 131, 8732-8733.

[2] van Deursen, R; L. Blum, J.-L. Reymond, J. Chem. Inf. Model. 2010, 50, 1924-1934. 
Medicinal Chemistry

MC 37

\section{Synthetic Oligonucleotide Probes to Elucidate Mechanisms of Translesion DNA Bypass}

\author{
Hailey L. Gahlon, Shana J. Sturla*
}

ETH Zürich, Schmelzbergstrasse 9, CH-8092 Zürich, Switzerland

DNA damage caused by reactions with dietary nitrosamines is implicated in cancer development. Persistent low-abundance lesions, with structures exemplified by the model biological adduct $\mathrm{O}^{6}$-Benzylguanine $\left(\mathrm{O}^{6} \mathrm{BnG}\right)$, if not repaired, become sources of coding information during polymerase mediated DNA replication. Specialized polymerases replicate past these DNA lesions; however the mechanism is often error-prone resulting in mutation. Understanding molecular level details of the mechanism of translesion bypass of $\mathrm{O}^{6} \mathrm{BnG}$ is a focus of this work. 3' modified oligonucleotide primers that base pair with $\mathrm{O}^{6} \mathrm{BnG}$ were evaluated for primer extension using the specialized polymerase DNA polymerase IV from Sulfolobus solfataricus (DPo4). Data regarding kinetic incorporation efficiencies and thermodynamic properties of nucleotide insertion will be presented. Computational modeling data offers additional insight regarding structural contributions and relative binding affinities between the adduct and synthetic oligonucleotides within the enzyme active site. Understanding mechanisms involved in bulky DNA lesion processing will help lead to better strategies for identifying low-abundance DNA adducts using nucleoside analogs as lesionspecific probes.
Medicinal Chemistry

MC 39

Contribution of Residue B24-26 for Insulin Activity and Stability relevant to its Pharmacology

Lixian Zhang, Markus Meuwly

Chemistry Department University of Basel, Klingelbergstrasse 80, CH-4056 Basel, Switzerland

Insulin is a 51-amino acid hormone that regulates the physiological glucose level in the blood. Before binding to its transmembrane insulin receptor, insulin must dissociate from its hexameric storage form through an intermediate dimer state to the bioactive monomer. On the other hand, the native insulin monomer is an active form that tends to aggregate to form dimers and hexamers in solution. Previous studie ${ }^{[1]}$ found that B24, B25, B26 residues in the monomer-monomer interface are important for the process of Insulin aggregation, but structure-activity relationships at these residues are not readily rationalized. ${ }^{[2,3]}$ Our study focused on the roles of these three residues with different substitutions by molecular dynamics (MD) simulations, normal mode analysis, binding free energy calculations and Monte Carlo simulations on the sidechain of those residues and their mutations. The influence caused by these different mutants leads to important insights and suggests which mutations influence the property of insulin for aggregation and maintain it in its monomeric pharmacologic active form.

[1] Mirmira, R. G., Nakagawa, S. H., and Tager, H. S., J. Biol. Chem. 1991, 266, 1428-1436.

[2] Hua, Q. X., Shoelson, S. E., Kochoyan, M., and Weiss, M. A., Nature 1991, 354, 238-241.

[3] Ludvigsen, S., Olsen, H. B., and Kaarsholm, N. C., J. Mol. Biol. 1998, 279, 1-7.
Medicinal Chemistry

MC 38

\section{Synthesis of new nAChR ligands}

Lise Bréthous, Sonia Bertrand, Daniel Bertrand and Jean-Louis Reymond*

University of Berne, Dept. of Chemistry \& Biochemistry, Freiestrasse 3, 3012 Bern, Switzerland.

In the past decade, there was a considerable interest in modulating nicotinic acetylcoline receptors (nAChRs) to treat cognitive dysfunction related pathologies (e.g., Alzheimer's disesase, Parkinson's disease , Schizophrenia..). ${ }^{1}$ Recently, we reported the synthesis of new nAChR ligands, which were derived from the docking of virtual analogues from the chemical universe database GDB- $11 .^{2}$ Thirty eight ligands were tested for modulation of the acetylcholine signal at the human $\alpha 7 \mathrm{nAChR}$ expressed in Xenopus oocytes, leading to competitive and noncompetitive antagonists with $\mathrm{IC}_{50}=5-7$ $\mu \mathrm{M}$. Here, we will present the synthesis of other new molecules derived from the GDB-13 and their activity on nACh receptors $(\alpha 7, \alpha 3 \beta 2, \alpha 4 \beta 2 .$.$) .$

[1] A. Taly, P.-J. Corringer, D. Guedin, P. Lestage, J.-P Changeux, Nat Rev. Drug Discov. 2009, 8, 733-750.

[2] N. Garcia-Delgado, S. Bertrand, K. T. Nguyen, R. van Deursen, D. Bertrand, J.-L. Reymond, ACS Med. Chem. Lett. 2010, 1, 422-426.

Medicinal Chemistry

MC 40

A Highly Enantio- and Stereoselective Synthesis of the BACE-1

Inhibitor A

Michael Hediger, Heinrich Rueeger and Siem Veenstra

Novartis AG, Postfach, CH4002, Basel

$\beta$-Secretase (BACE-1) is a membrane-bound aspartic protease responsible for the cleavage of amyloid precursor protein (APP) to generate A $\beta 40 / 42$ peptide fragments. Deposition of these $A \beta$-fragments ultimately leads to plaques associated with Alzheimer's disease. Therefore, inhibition of BACE-1 is thought to be a potential therapeutic target for the treatment of AD. A de novo design approach led to a novel class of BACE-1 inhibitors of the HEA (Hydroxy Ethyl Amine) type [1].

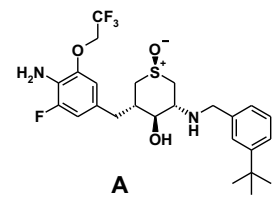

We developed a highly enantio- and diastereoselective approach for the synthesis of such inhibitors with the use of aldol methodology employing an Evans oxazolidinone chiral auxillary.

[1] Briard et al, WO2010003976. 
Medicinal Chemistry

PAMPA assessment for the prediction of passive transendothelial permeation of drug compounds and nanocarriers through the blood-brain barrier.

Céline Passeleu-Le Bourdonnec, Kévin Nadin, Cristina Pomilio, Florence Miller, Alessandra Zizzarri, Florence Délie, Eric Doelker, Pierre-Alain Carrupt, Sophie Martel

School of pharmaceutical sciences, University of Geneva, University of Lausanne, Quai Ernest Ansermet 30, CH-1211 Geneva (Switzerland)

The drug discovery process aiming at targeting the central nervous system suffers from one of the highest failure rate due to the presence of the bloodbrain barrier (BBB) and the highly represented transmembrane transporter proteins. Therefore, high-throughput screening techniques need to be developed to detect lead compounds disclosing good pharmacokinetics properties among a large set of drug candidates

Parallel Artificial Membrane Permeability Assay (PAMPA), relying on a specific immobilized artificial membrane separating to aqueous compartments, is a recent technique allowing the prediction of passive permeation through biological membranes [1] with high throughput efficiency.

In this study, PAMPA has been investigated for the development of a new artificial membrane predicting passive permeation of drug candidates through the BBB [2] and the evaluation of this membrane for the prediction of nanocarriers' passive permeation.

[1] Faller B. Current Drug Metabolism. 2008, 9, 886-892

[2] Passeleu-Le Bourdonnec C.; Boccard J.; Rudaz S.; Carrupt P. A. ; Martel S. In preparation

Medicinal Chemistry

MC 43

Tracking the penetration of topically applied actives in skin models by confocal Raman microscopy

\section{Franziska D. Fleischli, Stephanie Mathes, Christian Adlhart}

Zurich University of Applied Science ZHAW, Institute of Chemistry and Biological Chemistry, Einsiedlerstrasse 31, 8820 Wädenswil

The pathway and kinetics of skin penetration is an important factor in controlling the performance of topically applied pharmaceutical and cosmetic products. Recently confocal Raman spectroscopy has been established as non-invasive tool for characterizing the molecular composition of skin both in vitro and in vivo [1]. By Raman spectroscopy, the content of water, lipids, proteins, and amino acids is determined at different depths from the skin surface and thereby, the thickness and composition of the different skin layers. Depth scans are also used for monitoring the penetration of topically applied actives [2].

We investigated the molecular composition of the skin model "Episkin" from SkinEthic. In this model the dermis is reconstructed by a collagen matrix, while the epidermis is established by the differentiation of keratinocytes at the air-liquid phase. After 11 days of growth a functional barrier namely the stratum corneum (cornified top layer) is formed. Such skin models are used as substitute for human or animal skin in product studies [3]. We fully characterized the individual layers of the "Episkin" by highresolution confocal Raman mapping both the skin's surface and profiling the skin into the depth. The results are compared with microscopy data obtained from classically prepared and stained skin biopsies. To study the skin penetration of actives, lipophilic and hydrophilic, as well as liposomal packed compounds were topically applied on the "Episkin" and the penetration pathway was followed through the skin's layers.

[1] Caspers P.J. et al, Biophys $J$ 2003, 85, 572.

[2] Mélot M et al, J Controlled Release 2009, 138, 32 .

[3] Tfayli A. et al, Biopolymers 2007, 87, 261.
Medicinal Chemistry

MC 42

\section{${ }^{13} \mathrm{C},{ }^{2} \mathrm{H}$ enrichment of cholesterol for NMR applications}

Rupali Shivapurkar ${ }^{\mathrm{a}}$, Mohammadali Foroozandeh ${ }^{\mathrm{a}}$, Cleiton M. de Souza ${ }^{\mathrm{b}}$, Howard Riezman $^{\mathrm{b}}$, Damien Jeannerat ${ }^{\mathrm{a}}$

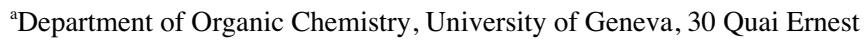
Ansermet, 1211, Geneva 4, Switzerland

${ }^{b}$ Department of Biochemistry, University of Geneva, 30 Quai Ernest Ansermet, 1211, Geneva 4, Switzerland

Cholesterol is one of the most important constituents of biological membranes and is implicated in the development of cardiovascular diseases. The structure of many complexes and structures involving cholesterol and its role in the formation of membrane microdomains are still unknown. We introduced an efficient biosynthesis and purification of ${ }^{13} \mathrm{C}$-enriched cholesterol using a strain of Saccharomyces cervisiae capable of synthesizing cholesterol $^{1}$ with a yield of c.a. $1 \mathrm{mg}$ of cholesterol per gram of glucose. We produced $96 \%$ and $10 \%$ labeled cholesterol 1 from $\left(\mathrm{U}_{-}{ }^{13} \mathrm{C}_{6}, 99 \%\right)$ glucose. The selective labeling at the 15 positions of the isotopomer 2 with $50 \%$ enrichment is possible using glucose enriched only at the carbon 1 .
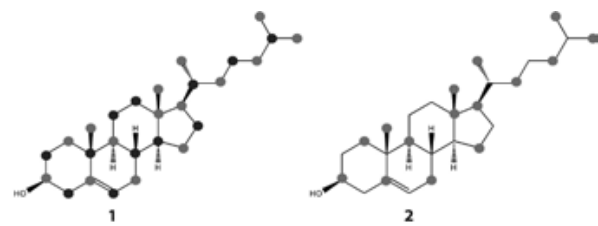

[1] R. Shivapurkar, C. M. Souza, D. Jeannerat, H. Riezman. Journal of Lipid Research 2011, 52, 1062-1065.

Medicinal Chemistry

MC 44

\section{Bifunctional Quorum Sensing Modulators: An Application Orientated Approach}

José Gomes, ${ }^{1}$ Alexander Grunau, ${ }^{2}$ Adrien K. Lawrence, ${ }^{1}$ Natalie Huber, Simon Glauser, ${ }^{1}$ Leo Eberl, ${ }^{2}$ Karl Gademann ${ }^{1, *}$

\footnotetext{
${ }^{1}$ University of Basel, St. Johanns-Ring 19, 4056 Basel, Switzerland

${ }^{2}$ University of Zurich, Zollikerstrasse 107, 8008 Zürich, Switzerland
}

Many types of bacteria possess a cell-to-cell signaling mechanism to assess their local densities referred to as quorum sensing (QS).$^{[1]}$ This signaling system is based on the intercellular exchange of small molecules called autoinducers. Hence, bacteria can monitor one another's presence and modulate gene expression in response to population density changes. Several of the most notorious human pathogens, including the Gram-negative bacteria $P$. aeroginosa, use $\mathrm{QS}$ to organize into biofilms and activate virulence pathways at high cell densities that are the basis for acute and chronic infections. The most common signaling molecules found in Gram-negative bacteria are $N$-acylated $L$-homoserine lactones (AHLs).

We designed and synthesized bifunctional AHL-analogues bearing a modulator moiety and a fluorescence marker. These chimeras have shown to be able to induce QS among others in the HLS biosensor strain Pseudomonas putida Iso $\mathrm{F} 117^{[2]}$ and also in the wild-type. In addition, these compounds are able to mark selectively Gram-negative bacteria bearing certain QSreceptors. We will present our results using these selective QS-receptor markers and the utility of these newly designed, bifunctional molecules.

[1] For reviews, see: a) J. S. Dickschat, Nat. Prod. Rep. 2010, 27, 343; b) M. B. Miller, B. L. Bassler, Annu. Rev. Microbiol. 2001, 55, 165; c) M. Hentzer, L. Eberl, J. Nielsen, M. Givskov, Biodrugs 2003, 17, 241.

[2] A. Steidle, K. Siegl, R. Schuhegger, A. Ihring, M. Schmid, S. Gantner, M. Stoffels, K. Riedel, M. Givskov, A. Hartmann, C. Langebartels, L. Eberl, Appl. Environ. Microbiol. 2001, 67, 5761. 
Medicinal Chemistry

Medicinal Chemistry

MC 46

\section{Electrically-assisted transdermal delivery of an anti-inflammatory agent}

Taís Gratieri ${ }^{1}$, Ester Pujol Bello ${ }^{1,2}$, Yogeshvar Kalia ${ }^{1}$

${ }^{1}$ School of Pharmaceutical Sciences, University of Geneva \& University of Lausanne, 30 Quai Ernest Ansermet, 1211 Geneva, Switzerland ${ }^{2}$ Faculty of Pharmacy, University of Barcelona, Barcelona, Spain

Ketorolac (KT) is a potent non-steroidal anti-inflammatory drug (NSAID) and analgesic indicated for the relief of pain as an alternative to opioids (1). KT is a small hydrophilic molecule $(376.41 \mathrm{Da}, \log \mathrm{P}-0.58, \mathrm{pKa} 3.5)$ that does not readily penetrate the skin. However, its physicochemical properties make it an excellent candidate for electrically-assisted delivery $(2,3)$. KT electrically-assisted delivery was investigated through porcine and human skin in vitro. Steady state flux across both skin models was statistically equivalent. Permeation from the cathode was linearly dependent upon both current density and drug concentration; in contrast, drug deposition showed no such dependence upon either parameter. The results demonstrated the feasibility of delivering therapeutic amounts of KT across the skin.

[1] M. Inoue, C.A. Caldarone, H. Frndova, P.N. Cox, S. Ito, A. Taddio, A.M. Guerguerian, Intensive Care Medicine, 2009, 35, 1584.

[2] Y.N. Kalia, A. Naik, J. Garrison, R.H. Guy, Adv Drug Deliv Rev. 2004, 56,619 .

[3] S.B. Tiwari, N. Udupa, Int J Pharm. 2003, 260, 93.

Medicinal Chemistry

MC 47

\section{Polyproline Based Cell Penetrating Peptides - A Tool for Intracellular Targeting?}

\section{Yvonne A. Nagel and Helma Wennemers*}

Department of Chemistry, University of Basel, St. Johanns-Ring 19, 4056 Basel, Switzerland

The effective delivery of drugs and other biomolecules into cells still holds challenges, since poor translocation across the plasma membrane is a major limitation for various applications. Recently developed cell penetrating peptides (CPPs) based on cationic amphiphilic polyproline structures might have the potential to address this issue. Exploiting the unique properties of oligoproline as a well-defined molecular scaffold ${ }^{[1]}$ we designed CPPs that bear guanidinylated moieties in various positions along the backbone of a polyproline II (PP II) helix (see figure). The efficient uptake into human cervical cancer cells (HeLa) was proved by fluorescence activated cell sorting (FACS). In order to investigate the mechanism of internalization, experiments at lower temperatur $\left(4{ }^{\circ} \mathrm{C}\right)$ and under ATP depletion were performed. Additionally we observed that the studied peptides do not only enter cells, but also show specific accumulation in the nuclei, which holds promise for intracellular targeting applications.

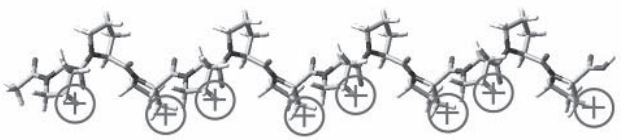

[1] a) Y. A. Nagel, M. Kuemin, H. Wennemers, Chimia 2011, in press; b) M. Kuemin, Y. A. Nagel, S. Schweizer, F. W. Monnard, C. Ochsenfeld, H. Wennemers, Angew. Chem. Int. Ed. 2010, 49, 6324-6327.

[2] For other related CPPs see: a) I. Geisler, J. Chmielewski, Chem. Biol. Drug. Des. 2009, 73, 39-45; b) B. A. Smith, D. S. Daniels, A. E. Coplin, G. E. Jordan, L. M. McGregor, A. Schepartz, J. Am. Chem. Soc. 2008, 130, 2948-2949.

\section{Smart vesicles for drug delivery \\ Isabelle Geissbuehler, Cécile Bonnaud}

University of Fribourg, Chemin du musée 9, 1700 Fribourg, Switzerland

Target drug delivery is of utmost importance for treating severe diseases and should allow: perfect containment of cargo molecules, specifically addressing the target, triggered release at the target and traceability. The aim of the project is to combine the favourable properties of lipid vesicles and superparamagnetic iron oxide nanoparticles (SPIONs) for drug release application [1]. Lipid vesicles enable to transport a large amount of drug and SPIONs (5-6 nm) allow traceability by MRI. The SPIONs inserted into the vesicle membrane can be heated up by an external magnetic field and locally destabilize the membrane resulting in a controlling in drug release [2]. First at all, liposoluble and monodisperse nanoparticles should be produced by a thermal decomposition [3]. Second aspect is formation of vesicle showing high biocompatibility and long residence time in the blood circulation, composed of a lipid mixture showing a transition phase temperature $(\mathrm{Tm})$ above $42^{\circ} \mathrm{C}$ to avoid release of the drug without the magnetic field and enabling incorporation of SPIONs. The third aspect of the project is to functionalize the vesicles with targeting factor. Circulating vesicles should selectively concentrate around the tumour and be detected by MRI, followed by drug release (in vitro and in vivo tests).

[1] E. Doelker, Biomaterials, 2010, 31 (4),691-705.

[2] Erik Reimhult, Nano Letters, 2011

[3] Taeghwan Hyeon, Nature Material, 2004, vol. 3
MC 48

Towards the site-specific chemical modification of the hERG channel Suradech Singhanat ${ }^{1}$ and Martin Lochner ${ }^{1}$

${ }^{1}$ University of Bern, Department of Chemistry and Biochemistry Freiestrasse 3, 3012 Bern, Switzerland

The hERG (Human $\boldsymbol{E}$ ther-a-go-go $\boldsymbol{R}$ elated $\boldsymbol{G}$ ene) encodes a potassium ion channel in several parts of the body, including the heart muscle where it is found to be critical for repolarization of cardiac tissue during the heart beat cycle $^{[1]}$. The detailed molecular structure of the hERG channel based on $\mathrm{x}$ ray crystallography is not yet available and derived from other potassium ion channels such as Shaker $(\mathrm{Kv} 1.1)^{[2]}$, computer models and mutagenesis studies. The use of photoaffinity probes such as 2-4 based on Dofetilide $\mathbf{1}$, a known high-affinity hERG channel blocker ${ }^{[3]}$, would allow a small molecule to covalently attach close to the channel pore. Further post-photoaffinity labeling modifications would offer the possibility to introduce a small flurophore near the channel pore. This would not only yield a biophysical tag for structural studies of the hERG channel block but could also provide a means for sensitive and rapid detection of potential channel blockers.

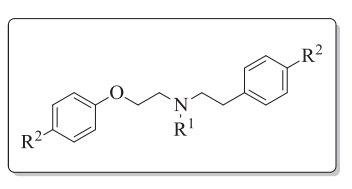

$$
\begin{aligned}
& \text { 1: } \mathrm{R}^{1}=\mathrm{Me} ; \mathrm{R}^{2}=\mathrm{NHSO}_{2} \mathrm{CH}_{3} \\
& \text { 2: } \mathrm{R}^{1}=\xi \mathrm{H}_{5}^{\mathrm{O}} \mathrm{R}^{3} ; \mathrm{R}^{2}=\mathrm{NO}_{2} \\
& \text { 3: } \mathrm{R}^{1}=\xi \mathrm{X}_{5}^{\mathrm{O}} \cdot \mathrm{R}^{3} ; \mathrm{R}^{2}=\mathrm{NH}_{2} \\
& \text { 4: } \mathrm{R}^{1}=\xi \mathrm{H}_{5}^{\mathrm{O}} \cdot \mathrm{R}^{3} ; \mathrm{R}^{2}=\mathrm{NHSO}_{2} \mathrm{CH}_{3}
\end{aligned}
$$

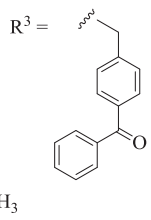

[1] D.H. Singleton et al., J. Med. Chem. 2007, 50, 2931.

[2] M.C. Sanguinetti, M. Tristani-Firouzi, Nature, 2006, 440, 463.

[3] G.J. Diaz et al., J. Pharmacol. Toxicol. Methods. 2004, 50, 187. 
Oligoproline as Multivalent Scaffold for Tumor Targeting Vectors

Carsten Kroll, Rosalba Mansi, Helmut R. Maecke and Helma Wennemers*

Department of Chemistry, University of Basel

St. Johanns-Ring 19, 4056 Basel, Switzerland

Overexpressed gastrin-releasing peptide receptors (GRP-R) on the surface of prostate and breast tumor cells are a valuable target for cancer diagnosis and treatment. Herein we present novel multivalent ligands, based on azidofunctionalized oligoprolines as helical, conformationally well-defined scaffolds. ${ }^{[1]}$ Multivalent tumor tracers are envisioned to provide longer residence times on the tumor cell compared to established monovalent agents. As targeting vectors bombesin agonists and antagonists are used. ${ }^{[2]}$ Labelling of the radiotracers with various radiometals allows for molecular imaging via PET and SPECT. A series of molecules, differing in type and composition of the targeting vectors has been synthesized.
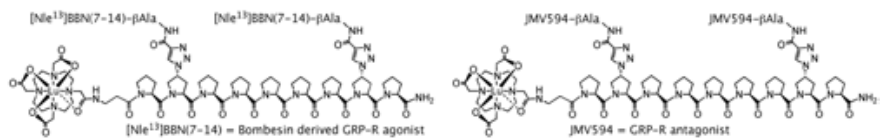

In vitro studies with ${ }^{177} \mathrm{Lu}$ labelled ligands show excellent binding and internalization. PET images of tumor-bearing mice with ${ }^{68} \mathrm{Ga}$ labelled ligands demonstrate the specific uptake in the tumor, underlining the ability of oligoprolines to serve as a scaffold with beneficial influence on the biological profile of the tracer.

[1] a) M. Kümin, L. S. Sonntag and H. Wennemers, J. Am. Chem. Soc. 2007, 129 , 566-567; b) Y. A. Nagel, M. Kümin, H. Wennemers, Chimia 2011, in press

[2] H. Zhang, J. Chen, C. Waldherr, K. Hinni, B. Waser, J. C. Reubi and H. R. Maecke, Cancer Res. 2004, 64, 6707.

\section{Medicinal Chemistry}

MC 51

Specific internalization of functionalized Superparamagnetic Iron Oxide Nanoparticles in Dendritic Cells using Optical Tweezers technique

\section{Anthony Redjem, Alke Fink}

University of Fribourg, Chemistry Department, Advanced Particles Group, 1700 Fribourg, Switzerland

The purpose of this study is to internalize functionalized Super Paramagnetic Iron Oxide Nanoparticles (SPIONs) produced by the University of Fribourg (Switzerland) in Dendritic Cells (DCs) from the University of Bern (Switzerland), using the Optical Tweezers (OT) technique developed in Ecole Polytechnique Fédérale de Lausanne (Switzerland)

Dendritic cells are primary cells first selected because as a model in order to further to develop a human Mesenchymal Stem Cells (hMSCs) study. The OT technique presents the advantage to specifically isolate DCs and hMSCs from a complex cell-ensemble which enhances considerably the uptake potential of SPIONs in those cells. In general, an immobilized cell in a 3D microenvironment allows for a variety of modifications and investigations: cell environment, cell morphology, and combination with magnetic tweezers in order to optimize the internalization, study of uptake pathway, fate of the particles upon cell differentiation, and real time monitoring in general.

All these parameters that can be investigated in order to considerably increase our understanding of NP-cell interactions in general and MSCs in particular. It will be also helpful for future researches in specific hMSCs targeting, drug discovery, and diagnostic.

Currently, OT has been designed and planed to co-operate the technique to facilitate/enhance the uptake of modified particle with different types of cells for in vitro study as well as to advance the uptake of the current cell of interest for example Stem cells.

\section{Synthesis of labeled stem-loop RNAs}

\section{A. Brunschweiger, L. Gebert, B. Guennewig, M. Rebhan, H. Towbin,} J. Hall

Institut für Pharmazeutische Wissenschaften, ETH Zürich, Wolfgang-Pauli-Str. 10, 8093 Zürich, Switzerland

The stem-loop RNA secondary structure, also called RNA hairpin, is an important motif occurring e.g. in the precursors of non-coding regulatory ribonucleic acids such as pre-microRNAs. There is evidence that this motif allows recognition of the structured RNA by certain RNA-binding proteins. For many analytical and pharmacological purposes it is therefore highly desirable to be able to place labels such as biotin or dyes at freely selectable positions within the sequence of stem-loop RNAs. A well-established method for the labeling of biomolecules is the Copper-catalyzed azide-alkyne cycloaddition (CuAAC). We synthesized a number of alkyne-modified phosphoramidate building blocks. These were incorporated into various premiRNAs allowing for attachment of biotin or dyes through CuAAC to these RNA-sequences. The labeled pre-miRNAs were subsequently used in biochemical and surface plasmon resonance-based binding assays.

Medicinal Chemistry

MC 52

Acetylcholine Receptor Organization in Membrane Domains in Muscle Cells: Evidence for rapsyn-independent and rapsyn-dependent mechanisms

Joachim Piguet, Christoph Schreiter, Jean-Manuel Segura, Horst Vogel, Ruud Hovius

Laboratoire de Chimie Physique des Polymères et Membranes Ecole Polytechnique Fédérale de Lausanne (EPFL) CH-1015 Lausanne, Switzerland

Nicotinic acetylcholine receptors (nAChR) in muscle fibers are densely packed in the postsynaptic region at the neuromuscular junction. Rapsyn plays a central role in directing and clustering $\mathrm{nAChR}$ during cellular differentiation and neuromuscular junction formation; however, it has not been demonstrated whether rapsyn is the only cause of receptor immobilization. Here, we used single-molecule tracking methods to investigate nAChR mobility in plasma membranes of myoblast cells during their differentiation to myotubes in the presence and absence of rapsyn. We found that in myoblasts the majority of nAChR were immobile and that $\sim 20 \%$ of the receptors showed restricted diffusion in small domains of $\sim 50 \mathrm{~nm}$. In myoblasts devoid of rapsyn, the fraction of mobile $\mathrm{nAChR}$ was considerably increased, accompanied by a 3-fold decrease in the immobile population of $\mathrm{nAChR}$ with respect to rapsyn-expressing cells. Half of the mobile receptors were confined to domains of $\sim 120 \mathrm{~nm}$. Measurements performed in heterologously transfected HEK cells confirmed the direct immobilization of nAChR by rapsyn. However, irrespective of the presence of rapsyn, about one-third of nAChR were confined in 300-nm domains. Our results show (i) that rapsyn efficiently immobilizes nAChR independently of other postsynaptic scaffold components; (ii) nAChR is constrained in confined membrane domains independently of rapsyn; and (iii) in the presence of rapsyn, the size of these domains is strongly reduced. 
Medicinal Chemistry

Design and testing of short 2'-O-methyl oligoribonucleotide inhibitors of microRNA maturation

Luca Gebert, Mario Rebhan, Andreas Brunschweiger, Jonathan Hall

ETH Zürich, IPW, Wolfgang-Pauli-Str. 10, 8093 Zürich, Switzerland

MicroRNAs are a class of small RNAs [1] involved in the regulation of pathways in development, metabolism and disease [2][3]. The last step of microRNA maturation is the processing by the RNase III type enzyme Dicer [4]. We developed an LCMS based assay for Dicer activity and used it to identify 2'-O-methyl antisense oligoribonucleotides (ASOs) with inhibitory properties [5]. The precursor of miR-122 was used as a model target; miR-122 is a liver-localized microRNA critical in the fatty acid metabolism, Hepatitis C Virus infection and hepatocellular carcinoma [6]. We showed that the binding position and the length of the antisense oligonucleotide (ASO) both influence inhibition strength. While very short (7mer) ASOs exhibited a low inhibitory effect, the best inhibitors identified so far were, surprisingly, not the longest ones. This insight was used to design improved inhibitors and to expand on new targets. Concurrently, cellular activity of the ASOs was investigated.

[1] Lee, R. C., Feinbaum, R. L., Ambros, V., Cell, 1993, 75, 843.

[2] Bartel, D. P., Cell, 2004, 116, 281.

[3] Weiler, J., Hunziker, J., Hall, J., Gene Therapy, 2006, 13, 496.

[4] Hutvágner, G., et al., Science, 2001, 293, 834.

[5] Gebert, L., Rebhan, M., Hall, J., SCS Fall Meeting 2010.

[6] Lewis, A. P., Jopling, C., Biochem. Soc. Trans., 2010, 38, 1553.
MC 55

Protein small-molecule conjugates as selective inhibitors of protein function

\author{
$\underline{\text { Birgit Mollwitz and Kai Johnsson }}$
}

The Mouse Eugenol Odorant Receptor: Structural and Functional Plasticity of a Broadly Tuned Odorant Binding Pocket

Olivia Baud,,${ }^{\ddagger}$ Sylvain Etter, ${ }^{\ddagger}$ Morena Spreafico,${ }^{\S}$ Lorenza Bordoli, ${ }^{\S}$ Torsten Schwede, ${ }^{\S}$ Horst Vogel, ${ }^{\ddagger}$ and Horst Pick

${ }^{\ddagger}$ Institut des Sciences et Ingénierie Chimiques, Ecole Polytechnique Fédérale de Lausanne, CH-1015 Lausanne, Switzerland

${ }^{\S}$ SIB Swiss Institute of Bioinformatics, Biozentrum der Universität Basel, CH-4056 Basel, Switzerland

Molecular interactions of odorants with their olfactory receptors (OR) are of central importance for the ability of the mammalian olfactory system to detect and discriminate a vast variety of odors with a limited set of receptors. How a particular OR binds and distinguishes different odorant molecules remains largely unknown on a structural basis. Here we investigated this question for mouse eugenol receptor (mOR-EG). By screening a large odorant library we discovered a wide range of chemical structures activating the receptor in heterologous mammalian cells. Potent agonists comprise (i) benzene-, (ii) cyclohexane- or (iii) polycyclic structures substituted with alcohol-, aldehyde-, keto-, ether- or esterified carboxylic groups. To detect those amino acids within the receptor, which are in contact with a particular bound odorant molecule, we investigated how distinct point-mutated mOREG were activated by the different odorant agonists, found for the wildtype receptor. We identified eleven amino acids as a part of the receptor's ligand binding pocket. Molecular modelling predicted ten of these residues in the transmembrane helices TM3-TM6 and one in the extracellular loop between TM2 and TM3. These amino acids participate in odorant binding with variable importance depending on the type of odorant, revealing functional 'fingerprints' of ligand-receptor interactions.

Medicinal Chemistry

\section{56}

\section{Subunit composition of the ionotropic serotonin receptor}

Ruud Hovius Joachim Piguet, Horst Vogel

Laboratory of Physical Chemistry of Polymers and Membranes Ecole Polytechnique Fédérale de Lausanne, Lausanne

The development of highly specific inhibitors is a daunting task, in particular when the protein of interest is a member of a large protein family like kinases or phosphatises [1]. Many inhibitors target the active site of a protein. In case of high structural similarity between protein family members this gives rise to off-target binding. It has been shown that mutations in the active site of the target protein can increase specificity [2] but this approach possesses a number of limitations, especially since it is not targeting the native protein. Therefore, we thought about a new way to generate selective inhibition by attaching a small-molecule inhibitor covalently to a carrier protein possessing itself affinity towards the target protein. As carrier protein we used loop mutants of SNAP-tag, a self-labelling protein-tag developed by our group [3]. Following a yeast two-hybrid screening approach we succeeded in isolating mutants that showed moderate binding affinity towards the target protein. Covalent labelling of the isolated SNAP-tag mutants with a small-molecule inhibitor generated an inhibitor complex that could inhibit the function of the target protein in an activity assay.

[1] Knight Z.A., Shokat K.M., Chem Biol 2005, 12, 621.

[2] Bishop C.A., Ubersax J.A., Petsch D.T., Matheos D.P., Gray N.S., Blethrow J., Shimizu E., Tsien J.Z., Schulz P.G., Nature 2000, 407, 396.

[3] Gronemeyer T., Chidley C., Juillerat A., Heinis C, Johnsson K., Protein Eng Des Sel 2006, 19(7), 309. 
Oligonucleotides bind to preferred sites in pre-microRNA structures

Mario A. Rebhan, Andreas Brunschweiger, Luca Gebert, Harry Towbin, Jonathan Hall

ETH Zürich, IPW, Wolfgang-Pauli-Strasse 10, 8093 Zürich

Post-transcriptional regulation by microRNAs (miRNAs, a novel class of short (21-23 nt) non-coding RNAs) plays an important role not only in natural development and function of organisms [1], but also in many disease mechanisms [2]. Precursors of microRNAs contain characteristic folded secondary structures with a long imperfectly double stranded region, from which processing enzymes generate the mature microRNA, and a loop of varying length. In order to explore the potential for pharmacological interference in this processing by short complementary oligonucleotides we carried out systematic binding studies to synthetic pre-microRNAs [3]. We used oligonucleotides of varying length and chemistry, which included RNA, DNA, and 2'- $O$-methoxy derivatives. Kinetic binding parameters were derived from surface plasmon resonance experiments on a recently developed instrument (SPR2, SierraSensors Inc.). The resulting binding affinity profiles indicated, as expected, generally higher accessibility in the loop region, but also, within that region, preferred sites that could be rationally explained on a structural basis. Thus, first experiments suggest that binding to these sites, which are located at the end or beginning of the predicted loop, generates an uninterrupted double helix by continuation of the stem. These hybrid structures appear to form a pseudo-half-knot [4], that may raise the selectivity of complementary oligonucleotides for miRNA precursors. Candidate oligonucleotides are currently being tested in biochemical and cellular assays.

[1] Bartel, D.P., Cell 2004, 116, 281-297.

[2] Weiler, J. et al., Gene Therapy 2006, 13, 496-502.

[3] Rebhan, M., Gebert, L., Towbin, H., Hall, J., SCS Fall Meeting 2010.

[4] Ecker, D.J. et al. Science, 1992, 257: 1669-78.

\section{Medicinal Chemistry}

MC 59

Assessment of the tissue oxygenation in vivo by measuring the luminescence lifetime of $\mathrm{Ru}(\text { Phen })_{3}{ }^{2+}$ as poorly photosensitizing probe

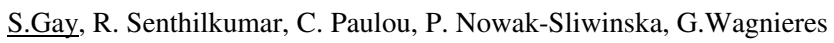

Medical Photonics Group, ISIC-EPFL, Swiss Federal Institute of Technology, 1015 Lausanne, Switzerland

Measurement of microcirculatory and tissular oxygen concentration in vivo is essential for the understanding of the determination of cellular respiration. One approach consists to assess this level of oxygen $\left(\mathrm{pO}_{2}\right)$ by measuring the luminescence lifetime of molecular probes. The quenching of the triplet state of such molecules enables to derive the $\mathrm{pO}_{2}$ using the Stern-Volmer Equation. Unfortunately, virtually all these oxygen sensitive probes induce some degree of phototoxicity which induces perturbations and tissue damage [1]. This is the reason why we have assessed, in vivo, the oxygen sensitivity as well as the phototoxicity of the oxygen sensor " $\mathrm{Ru}(\mathrm{Phen})_{3}{ }^{2+}$ ". The phototoxicity has been assessed with our Chorioallantoic membrane of chicken embryo model (CAM). The oxygen sensitivity of the $\mathrm{Ru}(\mathrm{Phen})_{3}{ }^{2+}$ has been assessed with the same in vivo model. Extravascular and intravascular compartments have been measured with an optical-fiber based timeresolved spectrometer described in details elsewhere [2]. Briefly, this compact setup consists of a nitrogen laser-pump, and tunable dye laser emitting in the UV-Vis part of the spectrum. Excitation and luminescence signals are carried out to and from the biological tissues by a single optical fiber. The detection is performed by a gated photomultiplier, which allows for timeresolved measurements of the luminescence intensity.

Our results indicate that: i) no phototoxic effects are observed as long as less than $5 \mathrm{~J} / \mathrm{cm}^{2}$ and $5 \mathrm{mg} / \mathrm{kg}$ are used as light and drug doses, respectively; ii) The $\mathrm{Ru}(\mathrm{Phen})_{3}{ }^{2+}$ demonstrates a significant $\mathrm{pO}_{2}$ dependence of its luminescence lifetime in vivo.

[1] Stepinac et al, Inv. Ophthalmology and Visual Science, 2005, 46, 956

[2] Piffareti, et al , J Biomed Opt, 2011, 16, 037005

\section{Multi-dimensional QSAR of uropathogenic E. coli FimH receptor an- tagonists}

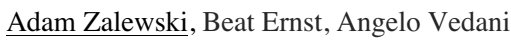

University of Basel, Klingelbergstrasse 50, CH-4056 Basel, Switzerland

Urinary tract infections (UTI) caused by uropathogenic E. coli are amongst the most prevalent infectious diseases, affecting millions of people each year. The currently applied antibiotical treatments are prone to development of bacterial resistance, calling for novel therapeutic approaches. Inhibition of the initial infection step - bacterial adhesion to the bladder mediated by mannose-specific FimH adhesins - using low molecular weight antagonists is one such approach.

Quantitative Structure-Activity Relationships (QSAR) may be employed to predict binding affinities of potential antagonists supporting the drug design process. In our study, we used compound poses identified by automated, flexible docking to the three-dimensional structure of the carbohydratebinding domain of FimH (PDB code 1UWF, $1.69 \AA$ resolution). The energetically most favorable poses were compiled into a 4D data set. A total of 89 compounds (66 training and 23 test compounds) were subjected to the 6D-QSAR software Quasar. The simulation converged at a cross-validated $r^{2}$ of 0.835 and yielded a predictive $r^{2}$ of 0.731 . The model was further challenged through y-scrambling, different sets of test compounds and consensus scoring (5D-QSAR software Raptor). The model will now be integrated into an automated framework (VirtualFimHLab) allowing medicinal chemists for a straightforward evaluation of any compound of interest.

[1] T. Klein, D. Abgottspon, M. Wittwer, S. Rabbani, J. Herold, X. Jiang, S Kleeb, C. Lüthi, M. Scharenberg, J. Bezencon, E. Gubler, L. Pang, M. Smiesko, B. Cutting, O. Schwardt, B. Ernst, J. Med. Chem. 2010, 53, 86278641.

[2] A. Vedani, M. Dobler, J. Med. Chem. 2002, 45, 2139-2149.

[3] A. Vedani, M. Dobler, L. Lill, J. Med. Chem. 2005, 48, 3700-3703.

Medicinal Chemistry

MC 60

In vivo Measurement of PPIX's Delayed Fluorescence Lifetime to Monitor Tissue Oxygen Concentration

F. Piffaretti, A.M. Novello, R. Senthil Kumar,

C. Paulou, P. Nowak-Sliwinska, H. van den Bergh, G. Wagnières

Medical Photonics Group, Swiss Federal Institute of Technology (EPFL), CH-1015 Lausanne, Switzerland

The partial pressure of oxygen $\left(\mathrm{pO}_{2}\right)$ in tissue plays an important role in the mechanisms taking place during photodynamic therapy (PDT). Therefore, monitoring this parameter is of high interest to predict the outcome of PDT. Since the triplet state of most photosensitizers used in PDT is quenched by molecular oxygen, and since many of them clinically do not exhibit a detectable phosphorescence, one original approach to monitor the $\mathrm{pO}_{2}$ consists of measuring the lifetime of their delayed fluorescence (DF). We report here the first real-time measurements, performed in vivo with a dedicated optical fiber-based time-resolved spectrometer. This compact setup consists of a nitrogen laser-pump, and tunable dye laser emitting in the UV-Vis part of the spectrum. Excitation and luminescence signals are carried out to and from the biological tissues by a single optical fiber. The detection is based on a gated photomultiplier, which allows for time-resolved measurements of the delayed fluorescence intensity and rejection of the promped fluorescence. In this study we measured the DF of protoporphyrin IX (PPIX), a photosensitizer in extensive clinical use. The $\mathrm{pO}_{2}$ was derived from the PPIX DF lifetime using the Stern-Volmer equation. PPIX production was induced in the chorioallantoic membrane (CAM) of the chicken embryo by a topically administrated aminolevulinic acid. PDT was induced with laser light $\left(\lambda_{\text {exc }}=405 \mathrm{~nm}\right)$. The results showed a decreasing oxygen concentration during the first $500 \mathrm{~s}$ of cumulated PDT time, while a limiting asymptotic value was reached at longer treatment times, very near to the zero concentration level of $\mathrm{pO}_{2}$. An excellent correlation between the therapeutic vascular damages and the $\mathrm{pO}_{2}$ reduction was found. 


\section{FimH Antagonists for the Treatment of Urinary Tract Infections}

Lijuan Pang, Said Rabbani, Simon Kleeb, Katrin Lemme, Beat Ernst*

Institute of Molecular Pharmacy, University of Basel Klingelbergstrasse 50, CH-4056 Basel, Switzerland

Urinary tract infection (UTI) by uropathogenic E. coli (UPEC) is one of the most common infections, affecting millions of people each year. Particularly affected are women, who have a $40-50 \%$ risk to experience at least one symptomatic UTI episode at some time during their life. The interaction of FimH - a lectin located at the tip of bacterial pili - with high mannose structures is critical for the ability of UPEC to colonize and invade the bladder epithelium. We describe the synthesis as well as the in vitro evaluation of low molecular weight $\alpha$-D-mannose derivatives with the ability to block the bacteria/host cell interaction. Starting from the orally available prodrug 1 [1], the enthalpy contribution to binding and the pharmacokinetic properties were further optimized. For the in vitro evaluation two different assays were applied, a target-based binding assay and isothermal titration calorimetry. Furthermore, the critical pharmacokinetic properties of the FimH antagonists $\left(\mathrm{p} K_{\mathrm{a}}\right.$, lipophilicity, solubility, gastrointestinal fluid stability, membrane permeation and plasma protein binding) were determined.

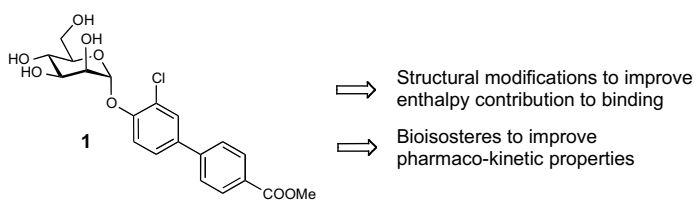

[1] T. Klein, D. Abgottspon, M. Wittwer, S. Rabbani, J. Herold, X. Jiang, S. Kleeb, C. Lüthi, M. Scharenberg, J. Bezençon, E. Gubler, L. Pang, M. Smiesko, B. Cutting, O. Schwardt, B. Ernst, J. Med. Chem. 2010, $53,8627-8641$.

Medicinal Chemistry

MC 63

Water soluble porphyrins linked with cisplatin analogues as novel photosensitizer for photodynamic therapy

Philipp M Antoni, Susmita Gupta, Pilar Ruiz-Sanchez, Bernhard Spingler

University of Zürich, Institute of Inorganic Chemistry, Winterthurerstr. 190, CH 8057 Zürich, Switzerland

Since the beginning of the 1990's, photodynamic therapy has extended the medicinal possibilities to fight cancer types that can be reached with red light. ${ }^{[1]}$ So far, there are only a few reports about combined photo- and chemotoxic therapies. Most of them show a synergistic effect. Furthermore, there are several reports about covalently linked conjugates of a photosensitizer with a cisplatin analog. Unfortunately, only prolonged light exposure allowed these conjugates to be phototoxic in the lower micromolar range. ${ }^{[2]}$ We have treated human cancer cell lines with novel porphyrin-platinum conjugates. The lowest determined $\mathrm{IC}_{50}$ value versus 2 human cancer cell lines was down to $0.08 \mu \mathrm{M}$ in the presence of red light. The light irradiation increased the toxicity by a factor up to 57 compared with dark toxicity for the conjugates. Furthermore, this corresponds to a ten-fold higher toxicity than cisplatin alone. As the PS of choice, cationic porphyrins have been selected due to their water solubility, cellular and nuclear uptake. In addition, the central metal allows tuning the visible absorption bands.

Despite impressive progress in the field of the chemotherapy, there is still the immediate need for a bifunctional drug that combines the advantages of photodynamic therapy and platinum based chemotherapy.

[1] M. R. Hamblin, P. Mroz, in Advances in Photodynamic Therapy Artech House Publishers: 2008; p 559.

[2] J. F. Mao, Y. M. Zhang, J. H. Zhu, C. L. Zhang, Z. J. Guo, Chem Commun. 2009, 908-910.

\section{Palladium-Mediated Intracellular Chemistry}

Emma. Johansson, M. Rahimi Yusop, Asier Unciti-Broceta, Rosario M. Sanchez-Martin, Mark Bradley

EastChem School of Chemistry, The Kings Buildings, University of Edinburgh, West Mains Road, Edinburgh EH9 3JJ,UK

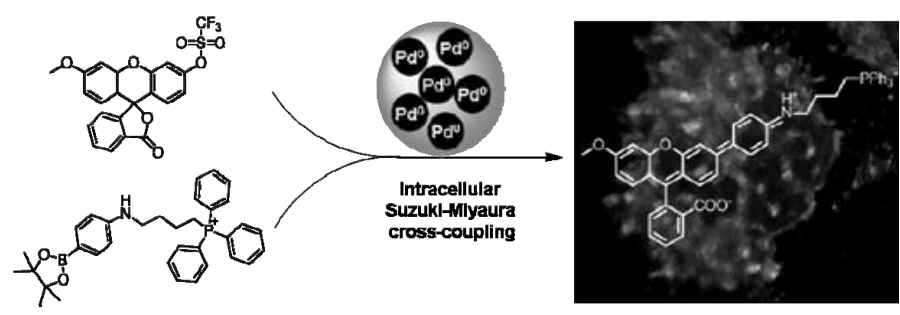

A novel non-toxic heterogeneous palladium catalyst able to carry out Suzuki-Miyaura cross-coupling reactions under physiological conditions (in vitro) is presented. Palladium nanoparticles ${ }^{1}$ encapsulated on polystyrene microspheres ${ }^{2,3}$ act as a catalysts which opens up a plethora of intracellular applications ranging from labeling to in situ synthesis of novel drugs. ${ }^{4}$

[1] J. K. Cho, R. Najman, T. W. Dean, O. Ichihara, C. Muller, M. Bradley, J. Am. Chem. Soc., 2006, 128, 6276.

[2] R. M. Sanchez-Martin, M. Cuttle, S. Mittoo, M. Bradley, Angew. Chem. Int. Ed., 2006, 45, 5472.

[3] L. M. Alexander, R.M. Sanchez-Martin, M. Bradley, Bioconjug. Chem., 2009, 20, 422.

[4] R. M. Yusop, A. Unciti-Broceta, E. M. V. Johansson, R. M. SánchezMartín, M. Bradley, Nature Chemistry, 2011, 3, 239.

\section{Medicinal Chemistry}

MC 64

Mechanistic and Inhibition Studies on $\boldsymbol{\gamma}$-Butyrobetaine Hydroxylase Using Synthetic Substrate Analogues

Luc Henry, Ivanhoe K. H. Leung, Timothy D. W. Claridge, Christopher J. Schofield

Department of Chemistry, University of Oxford, Chemistry Research Laboratory, Mansfield Road, Oxford, OX1 3TA, United Kingdom

L-Carnitine plays an essential metabolic role in animals by enabling the active transport of long chain fatty acids into the mitochondria. The final step of its biosynthesis is catalysed by $\gamma$-butyrobetaine $(\gamma \mathrm{BB})$ hydroxylase (BBOX), an iron/2-oxoglutarate (2OG) dependant oxygenase [1]. Inhibition of BBOX by 3-(2,2,2-trimethylhydrazine)propionate (THP) has been shown to have beneficial effects $[2,3]$ but no clear mechanism was proposed.
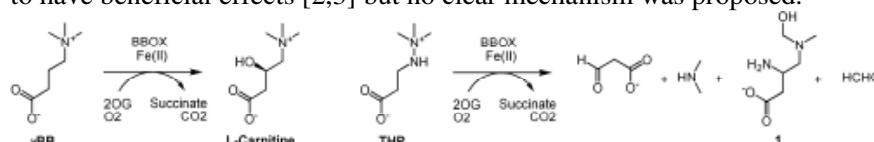

We carried biochemical characterization of the enzyme activity using an assay based on ${ }^{1} \mathrm{H}$ NMR. Synthesis of a series of $\gamma \mathrm{BB}$ and THP analogues gave insights in the substrate specificity of BBOX and indentified THP as a competitive substrate. Using a combination of MS and NMR experiments and with the help of synthetic ${ }^{13} \mathrm{C}$ labeled THP, product $\mathbf{1}$ was found to contain a new carbon-carbon bond resulting from an unprecedented reaction involving N-demethylation coupled to oxidative rearrangement [4].

Alongside with crystallographic data, these results provide insights into Lcarnitine biosynthesis at the molecular level and will enable the development of improved BBOX inhibitors.

[1] Vaz, F.M., and Wanders, R.J.A. Biochem. J. 2002, 361, 417-429.

[2] Dambrova, M. et al. Trends Cardiovasc. Med. 2002, 12, 275

[3] Pupure, J. et al. Neuroscience Lett. 2010, 470, 100

[4] Leung, I. K. H. et al. Chemistry \& Biology 2010, 17, 1316-1324 
Medicinal Chemistry

MC 65

Protease-Sensitive NanoMicelles for Targeting of Prostate Cancer

Magdalena A. Swiderska ${ }^{1}$, Karine Mondon ${ }^{1}$, Maria Fernanda Zuluaga ${ }^{1}$, Michael Möller ${ }^{1}, \underline{\text { Hubert van den Bergh }}{ }^{2}$, and Norbert Lange ${ }^{1}$

University of Geneva, 30, Quai Ernest Ansermet, CH-1211 Geneva, Switzerland, ${ }^{2}$ EPFL, Station 6, CH-1015 Lausanne, Switzerland

Prostate cancer is still one of the mostly diagnosed forms of cancer diagnosed in men. Currently, there is no satisfying treatment on the market for men suffering from metastatic disease. This can be ascribed, at least partially to unsuitable selectivity of most conventional anticancer agents.

Previous work has shown the selective delivery of photoactive drugs through proteolytic activity in animal models for prostate cancer and rheumatoid arthritis. [1,2]

Our present research is focused on the extension of protease-mediated drug delivery to other anticancer agents for the treatment of metastasized prostate cancer. Since covalently bound drugs may have considerably different pharmacological properties, we have developed protease-sensitive nanomicelles. These nanocarriers are based on micelle-forming triblock copolymers that effectively encapsulate lipophilic drugs. The lipophilic core of these nanomicelles is composed of the hexPLA, while the hydrophilic PEG chains in the periphery of these nanomicelles lead to their water solubility as well as their plasma stability. The peptide linker in between the two polymers is conceived to be selectively digested by target proteases. Primary selectivity is achieved by enhanced penetration and retention effect provided by these nanomicellar systems. Furthermore, in the presence of proteases, the PEG polymer side chain will be cleaved from the nanomicelles leaving the lipophilic core containing the drug payload as a deposit at the site of cleavage.

[1] Gabriel D, Zuluaga MF, van den Bergh H, Gurny R, Lange N. Curr Med Chem. 2011;18:1785-805.

[2] Gabriel D, Busso N, So A, van den Bergh H, Gurny R, Lange N. J Control Release. 2009;138:225-34 